\title{
Non-linear static procedures applied to high-rise residential URM buildings
}

\author{
R. Gonzalez-Drigo $^{(1)(*)}$, J. Avila-Haro ${ }^{(1)}$, L.G. Pujades ${ }^{(2)}$ and A.H. Barbat $^{(2)}$ \\ ${ }^{(1)}$ Dept. of Strength of Materials and Structural Engineering. UPC BarcelonaTech. Barcelona, Spain \\ ${ }^{(2)}$ Dept. of Civil and Environmental Engineering. UPC BarcelonaTech. Barcelona, Spain

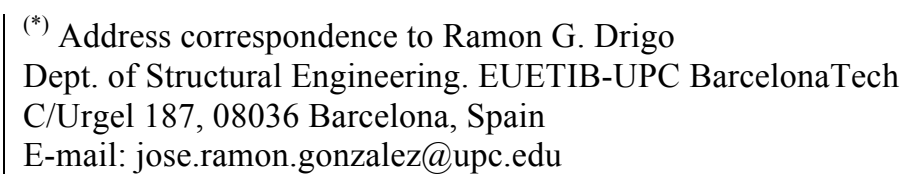

\begin{abstract}
In this work, the vulnerability of an unreinforced masonry building, evaluated on the one hand by using the incremental dynamic analysis, and on the other hand by using nine representative non-linear static incremental procedures, is compared. For comparison reasons among the different non-linear static procedures, the obtained incremental dynamic analyses results are used as reference values. The aim of this analysis is to evaluate the applicability and reliability of the diverse non-linear static procedures for unreinforced masonry buildings, and to propose modifications oriented to improve their use in this typology of structures. For this purpose, a fully representative unreinforced masonry building of the dominating building type in the Eixample district of Barcelona, is analyzed. Furthermore, the conditional spectrum approach procedure has been applied with the aim to conveniently define the seismic demand. Regarding the definition of the fragility curves, two different methodologies were used for each non-linear static procedure and incremental dynamic analyzes. Subsequently, the corresponding damage indices as well as the damage curves were calculated and compared for the different considered peak ground acceleration values. The results of this comparison seem to confirm that the damage curves obtained by performing the NSP and by applying the Risk-UE methodology overestimate the damage corresponding to low values of the PGA and underestimate the damage for higher values of the PGA.
\end{abstract}

Keywords: Unreinforced masonry; push-over; non-linear static procedures; multi stripe analysis; vulnerability

\section{INTRODUCTION}

To evaluate the seismic vulnerability of existing buildings and based on the knowledge level of the parameters of interest (e.g., geometric characteristics, mechanical properties and structural details), a number of methods have been developed and incorporated in different guidelines, among which we can mention GNDT (GNDT 1994; Bernardini 2000), Risk-UE (Lagomarsino and Penna 2003; Giovinazzi and Lagomarsino 2002), HAZUS (FEMA/NIBS 1999; HAZUS 2012) and GEM (D'Ayala et al. 2015).

The early methods are based on the classification of the structural behavior obtained from the observation, analysis and assessment of damaged buildings hit by earthquakes. Expert opinion is taken into consideration as an important aspect of these practices. An example of these approaches is the vulnerability index (Benedetti and Petrini 1984; Barbat et al. 1996; Lantada et al. 2009; Lantada et al. 2010; Barbat et al. 2010; Barbat et al. 2011) in which the seismic action is defined by means of a macroseismic intensity (EMS-98 1998), and the structural response is classified using the weighted sum of numerical values given to structural and non-structural parameters that play an important role in the seismic behavior of the structure. 
Another group of methods is based on a static approach to the seismic performance of the building. These methods define the seismic action through an elastic or inelastic response spectra, and the performance of the building is described in terms of the capacity curve which is calculated from a nonlinear static incremental analysis.

Different methodologies based on the capacity curve have been proposed. These methodologies involve simple techniques that can be implemented with relative ease to estimate the building's performance.

Recently, with the rapid development of the computational methods and computing processors, a methodology known as the Incremental Dynamic Analysis (IDA) has become of common use to evaluate the dynamic behavior of structures subjected to seismic actions defined by means of acceleration time histories. The method was developed by Vamvatsikos and Cornell (2002), and aims to obtain a measurement of the structural damage corresponding to the successive increments of the intensity of the seismic action, obtained by scaling ground motion records through a range of different peak ground acceleration (PGA) values. For each PGA increment, the dynamic response of the building is described through a kinematic control variable which usually consists of a maximum displacement measured, for example, at the roof of the building.

The work carried out in this paper compares the vulnerability and expected damage of an unreinforced masonry (URM) building evaluated by the IDA approach, and by different Non-linear Static Procedures (NSPs). The results obtained from the IDA will be used as reference values in the comparison with the results of six selected NSPs which have been chosen due to their importance, acceptance and applicability. The aim of this analysis is to evaluate the relevance and reliability of the NSPs applied to URM buildings, and to propose, if possible and in some cases, modifications oriented to improve their use within this type of structures.

The URM building analyzed in this study is fully representative of the dominating building type for the period from 1890 to 1940 in the Eixample district of the city of Barcelona (Spain). This typology consists of bearing walls of solid clay bricks connected by floors solved with unidirectional slabs of iron beams covered by brick vaults.

The aim of this work is to compare different static procedures and, in order to avoid additional uncertainties in the analysis associated to the materials and geometry, a deterministic approach was undertaken using specific values for these variables in the studied building.

Regarding the geometric variability, the number of storeys and the storey height were strictly regulated by the council building ordinances at the time. (Garcia Espuche 1990; Busquets and Corominas-Ayala 2009; Centre de Cultura Contemporània de Barcelona (CCCB)). Thus, it can be stated that the analyzed building is fully representative of the typology of URM buildings of seven levels corresponding to the construction period of interest (1890-1940).

The conditional spectrum approach procedure (Abrahamson and Al Atik 2010; Jayaram et al. 2011; NIST 2011) was applied to select six horizontal acceleration components from the PEER earthquake database (PEER 2011), matching the site-specific target response spectrum corresponding to the soil type II of the city of Barcelona. For soil types description see, for instance, Lantada et al. (2009, 2010).

The structural analyses are then performed for the different NSPs and the IDA, and their corresponding fragility functions and damage curves are obtained for the six scaled ground motions for two different intensity measures (IMs): the spectral displacement, $S_{d}$, and the PGA. The soilstructure interaction (see for instance Pecker 2007) has not been considered in this work. 


\section{METHOD}

\subsection{Earthquake scenario}

According to the handbook of the European project RISK-UE (Milutinovic and Trendafiloski 2003), two methods can be applied for the seismic hazard assessment depending on the parameters to be used to define the seismic demand: macroseismic intensity or spectral values, respectively (Lantada et al. 2009). Both approaches can be carried out for deterministic and probabilistic scenarios.

For the purpose of this work, the spectral values method and a deterministic scenario for the expected ground-shaking in the City of Barcelona were chosen. The deterministic scenario has been drawn up on the basis of two reference earthquakes: a) The 1428 earthquake (Eastern Pyrenees) with an epicentral distance of $90 \mathrm{~km}$, a MSK intensity of IX, and a focal depth of $10 \mathrm{~km}$; and b) The 1448 earthquake (Cardedeu in the nor-eastern Iberian coast) with an epicentral distance of $25 \mathrm{~km}$, a MSK intensity of VIII, and a focal depth of 7 km (Susagna and Goula 1999; Secanell et al. 2004).

As a final result of the numerous studies performed for the seismic characterization and microzonation of Barcelona (Secanell et al. 1998; Cid 1998; Secanell et al. 2004), an analytical formulation for the different $5 \%$ damped response spectra corresponding to different soil types was developed by Irizarry et al. (2003), allowing to represent reliable demand levels for the deterministic case (Fig.1).This is the formulation used in this article.
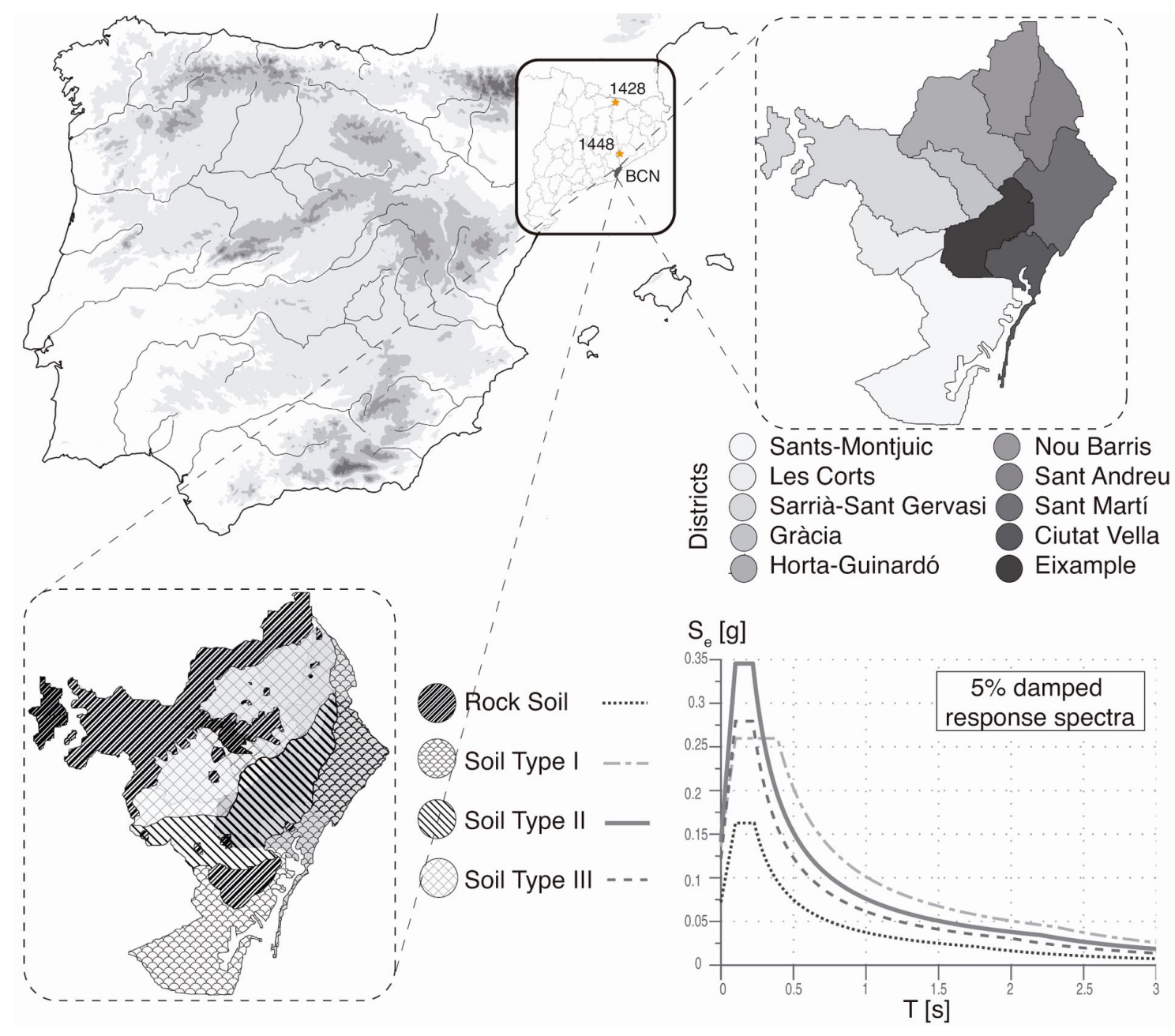

Fig. 1. Reference earthquakes for the deterministic scenario demand, including the districts and the seismic zonation of Barcelona with the corresponding 5\% damped response spectra 


\subsection{URM building and pushover analysis}

Nowadays, the Eixample district of Barcelona has 247418 inhabitants, a population density of 33148 inhabitants $/ \mathrm{km}^{2}$ and 8658 buildings. Nearly $73 \%$ of the buildings of the Eixample are URM buildings and, on average, they have 7 stories. The average year of construction of all the buildings of the Eixample is 1931; because of this, a large number of masonry buildings are more than 100 years old (Lantada 2007). Their architectural and structural features have been studied and modeled taking into account the guidelines and judgment of experts, the use of recent technical reports, original floor plans, architectural drawings and documents from the databases of the Council and the Architecture College of the City of Barcelona (Pujades et al. 2012; González-Drigo et al. 2015). In some cases, this information was completed by performing noninvasive prospective researches (González-Drigo et al. 2008; Pérez-García et al. 2012). The seismic performance of these URM buildings has also been the subject of other studies (González-Drigo et al. 2015).

The representative URM building of Fig. 2 belongs to a block of aggregated buildings situated in Soil Zone II. It was constructed in 1934 and was chosen for this work because it summarizes the main characteristics of the URM buildings of the Eixample district. It has an open and clear base level with high ceilings, mainly used for commercial purposes (Fig. 2.b) The upper stories are commonly used for housing, have a lower height and bearing walls with symmetrical openings in accordance to the central core of the structure (Fig. 3).
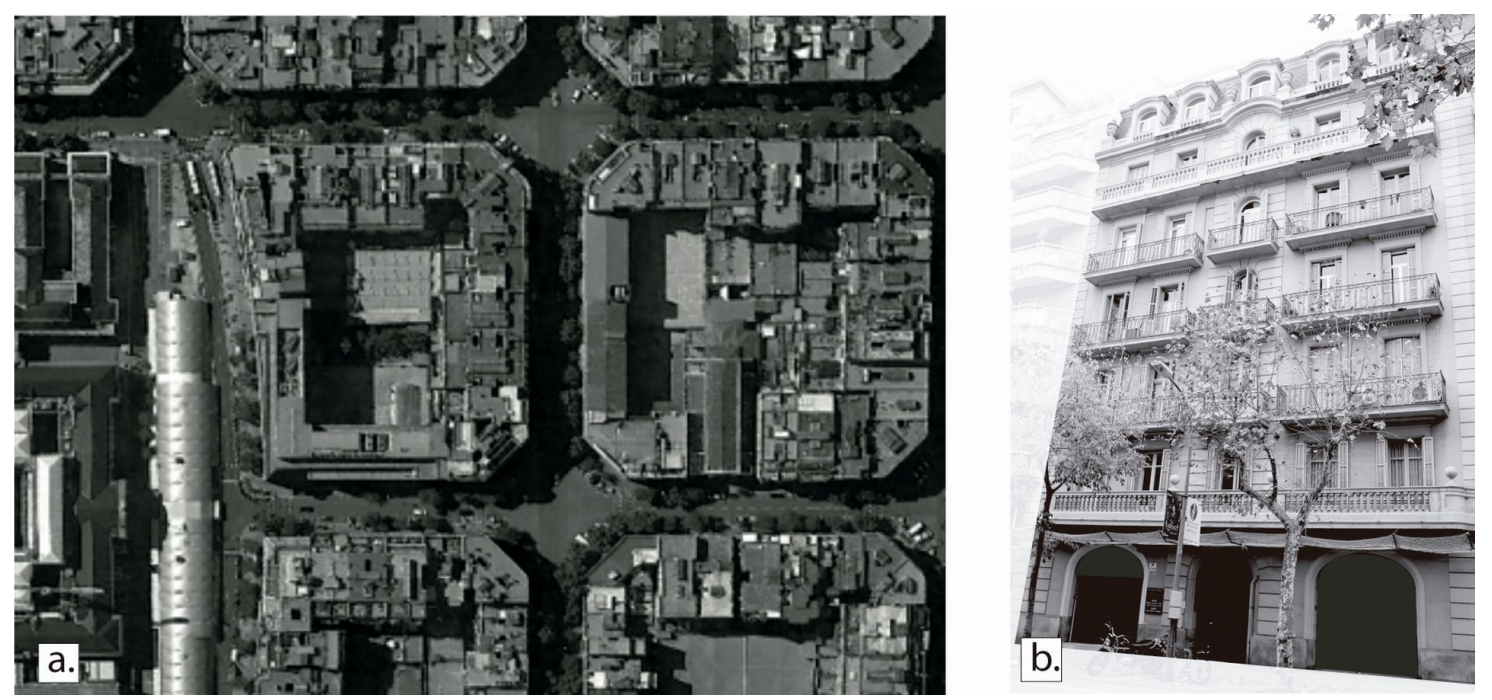

Fig. 2. Analyzed building located in Barcelona. a) Aggregate; b) Façade 


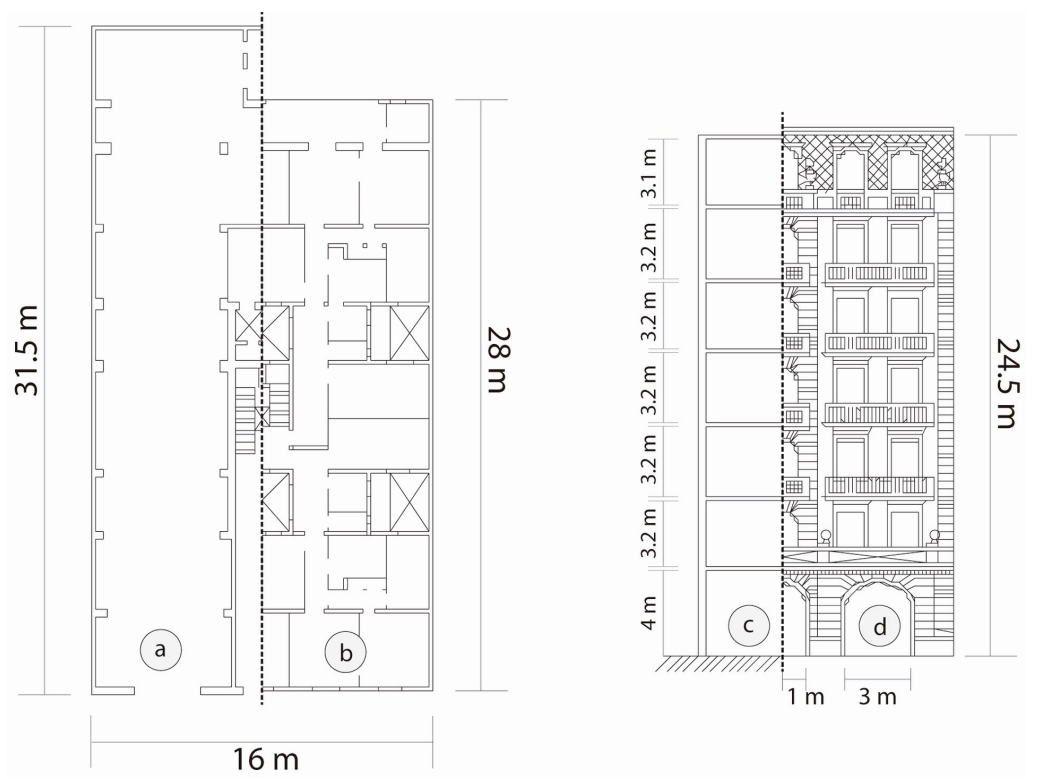

Fig. 3. The analyzed building. Architectural floor plans a) Ground floor; b) Intermediate floor; c) Side elevation; d) Front façade [dimensions are in $\mathrm{m}$ ]

In order to allow more open and wider spaces, the load on the base level is distributed through metallic beams and columns, avoiding therefore as much as possible, the presence of walls (Fig. 5). For the upper levels (Fig. 3.c and Fig. 5), the load is distributed via a load bearing walls system mainly conformed of: 1) façade walls, with a thickness of 45 to $60 \mathrm{~cm}$ at the base level, and a thickness of 30 $\mathrm{cm}$ for the upper stories; 2) lateral or intermediate walls, with a thickness of $30 \mathrm{~cm}$ at the base level and a thickness of $15 \mathrm{~cm}$ for the upper levels; 3 ) the central core of the building with an homogeneous thickness of $30 \mathrm{~cm}$ for all the stories, and 4) the internal load bearing walls, with a thickness of 10 to $15 \mathrm{~cm}$. Depending on the width of the wall, a header or stretcher bond can be found in the brickwork, characterized with a $1 \mathrm{~cm}$ wide head joint. Big openings, usually found in the façade walls (Fig. 3.a), were solved with metallic lintels and sometimes withy masonry arches. For smaller openings, like windows and doors, the use of wood lintels was common.

The floor system was mainly built with metallic girders, oriented in parallel with the shorter direction of the area to be covered, and separated by brick vaults with an opening of 70 to $80 \mathrm{~cm}$. The presence of an additional compression layer on the top of the floor system was usual.

For the purpose of this work, the selected representative URM building was modeled as an isolated structure by using the TreMuri program (Galasco et al. 2002), following the established criteria for the constitutive laws definition. The applied hysteretic law in this work (Fig. 4) considers the stiffness degrading (SD) with a low level of dissipation (associated with a plastic internal force, $f_{y}=0.2$ ) and a softening parameter $\beta=0$ (Gambarotta and Lagomarsino 1997a; Penna 2002). Out-of-plane behavior/failure of the walls is not considered in this work.

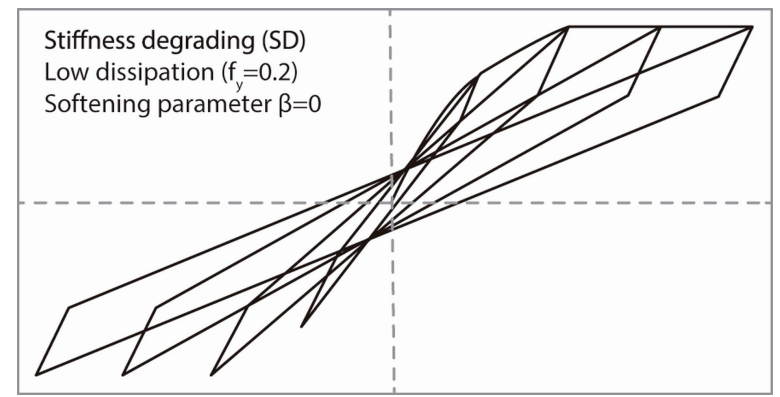

Fig. 4. Non-linear hysteretic model (from Gambarotta and Lagomarsino (1997a)) 


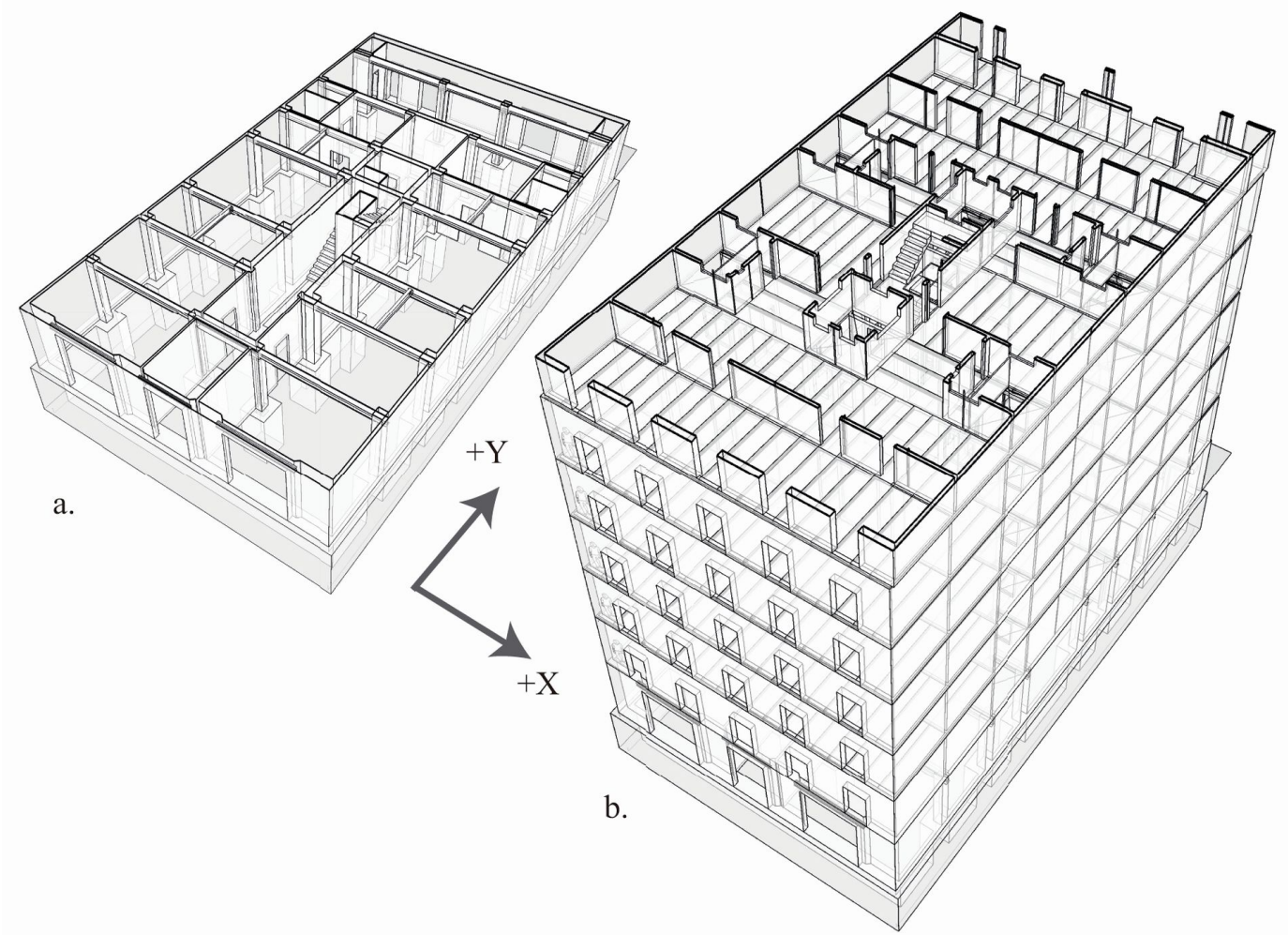

Fig. 5. Tridimensional view of the analyzed building a) base level; b) upper levels

There is an important variability of the mechanical properties of the materials used in these URM buildings. The main causes are the intrinsic variability in the properties of the mortar used at that time, the quality of the source materials used in the manufacturing of the bricks and the heterogeneities of the physical/environmental conditions during the process of brick firing (PIET-70 1971; Paricio 2001; Pujades et al. 2012; González-Drigo et al. 2015). The adopted values of the mechanical properties of the materials considered in the model are in the range of the corresponding values obtained through tests performed in samples of contemporary masonry (PIET-70 1971; Paricio 2001). Existing masonry is considered in the model, with uncracked stiffness. These values are shown in Table 1.

Table 1. Average value of the mechanical parameters used to characterize the brickwork of the analyzed URM building

\begin{tabular}{ll}
\hline Mechanical parameters & Average value \\
\hline Specific weight $\gamma$ & $18 \mathrm{kN} / \mathrm{m}^{3}$ \\
Elastic modulus E & $2650 \mathrm{MPa}$ \\
Shear Modulus G & $590 \mathrm{MPa}$ \\
Shear strength $\tau$ & $7.95 \times 10^{-2} \mathrm{MPa}$ \\
Compressive strength $\mathrm{f}_{\mathrm{m}}$ & $2.65 \mathrm{MPa}$ \\
\hline
\end{tabular}

Regarding the modal and the pushover analysis of the structure, a monotonic load pattern proportional to the first mode was assumed. The selected control node is located in the mass center of the roof level. The analysis was performed independently for the two main directions, $+X$ (parallel to the front façade/street) and $+Y$ (orthogonal to the front façade/street) ( Fig. 5).

Due to the box-behavior of this type of buildings, and that more than the $90 \%$ of the mass is activated by the first three significant modes for each considered direction $(\mathrm{X}, \mathrm{Y})$, the influence of higher modes can be neglected, and, therefore, the structural behavior is predominantly influenced by the first mode (Barbat 1982; Priestley et al. 1996; Barbat and Bozzo 1997; Barbat et al. 2005; Fardis 2009). 
As it can be seen in Table 2 the behavior of the building is governed by the first mode in each direction, $\mathrm{X}$ and $\mathrm{Y} .87 .21 \%$ and $74.31 \%$ of the mass is activated in $\mathrm{X}$ and $\mathrm{Y}$ directions, respectively.

Also a translational behavior can be observed in accordance with the corresponding Importance Factors (IF) for each direction, which represents the ratio between the involved mass in a specific direction and the total mass involved in all directions for each analyzed mode.

Table 2. Modal analysis. Fundamental modes for each direction, $\mathrm{X}$ and Y.

\begin{tabular}{|c|c|c|c|c|c|c|c|c|}
\hline Direction & Mode & Period T [s] & Mx [kg] & My [kg] & IFx [\%] & IFy [\%] & Мх [\%] & Мy [\%] \\
\hline \multirow{3}{*}{$\mathbf{X}$} & 1 & 0.54 & 2197037 & 403 & 99.981 & 0.018 & 87.21 & 0.02 \\
\hline & 2 & 0.19 & 255066 & 4 & 99.996 & 0.002 & 10.12 & 0.00 \\
\hline & 3 & 0.10 & 34918 & 54 & 99501 & 0.154 & 1.39 & 0.00 \\
\hline & & & & & & $\Sigma$ & 98.72 & \\
\hline \multirow{4}{*}{$\mathbf{Y}$} & 1 & 0.55 & 467 & 1872181 & 0.025 & 99.975 & 0.02 & 74.31 \\
\hline & 2 & 0.18 & 2 & 350873 & 0.001 & 99.999 & 0.00 & 13.93 \\
\hline & 3 & 0.11 & 5 & 69973 & 0.002 & 26.361 & 0.00 & 2.78 \\
\hline & & & & & & & $\Sigma$ & 91.02 \\
\hline
\end{tabular}

The selected NSPs for this comparison work share a common hypothesis where the structural behavior is mainly represented by the first vibration mode. The behavior of the studied building accomplishes this assumption. In the case of significant influence of higher modes, different variants or adaptations of the existing NSPs can be found in the literature (Kreslin and Fajfar 2012).

For the purposes of this study, an average period of $0.54 \mathrm{~s}$ was used for the record selection algorithm (NIST 2011) which is explained in section 2.3.

The steps involved in the transformation of the Multiple Degree of Freedom (MDOF) system into a Single Degree of Freedom (SDOF) system, and therefore, the factors needed for the conversion of the capacity curve (pushover curve) to the acceleration-displacement format, vary depending on the NSP to be applied. Capacity drops of the pushover curve are related to the increase of local damage in some specific walls. The capacity curves and the capacity spectra of the analyzed URM building are shown for both directions in Fig. 6. 

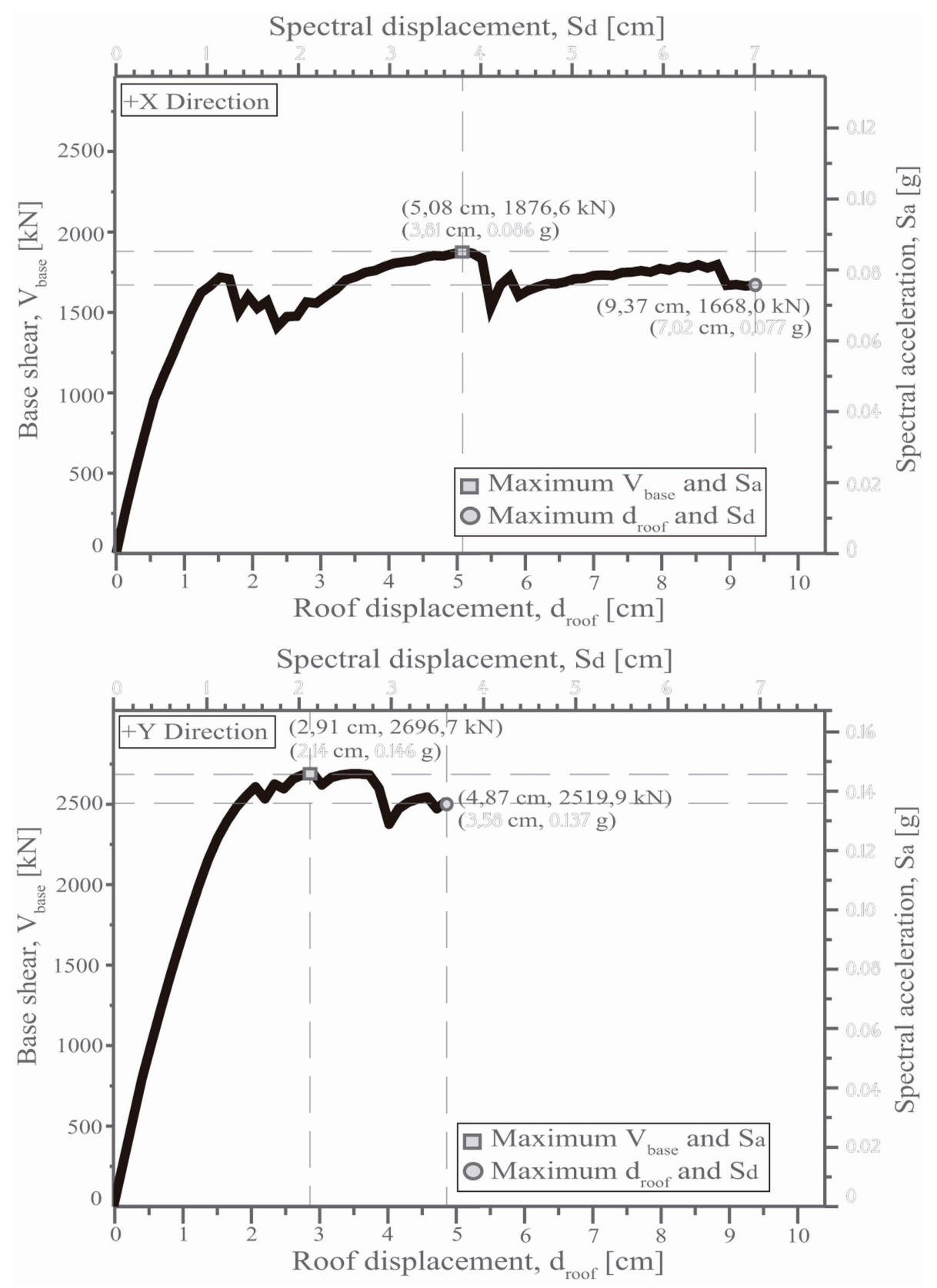

Fig. 6. Capacity of the URM building. Pushover curve $\left(V_{\text {base }}\right.$ vs. $\left.d_{\text {roof }}\right)$ and spectral format $\left(S_{a} v s . S_{d}\right)$. a $)+X$ direction; b) $+Y$ direction

\subsection{Record selection}

The lack of damage data in Spain hampers the comparison between numerical predictions and observed damages. Additionally, the typology and demand of registered events in Spain do not match those expected in Barcelona.

The 5\% damped response spectra for Soil Zone II of Barcelona was considered as the site-specific target response spectrum for the selection of six non-scaled matching horizontal acceleration components obtained from the PEER earthquake database with the Conditional Spectrum (CS) approach (Abrahamson and Al Atik 2010; PEER 2011; Jayaram et al. 2011; NIST 2011). These ground motion records, included in Table 3, match the criteria of conditional mean and conditional variability for a specific selected period as it can be seen in Fig. 7. The PEER database was preferred 
since the features of the accelerograms available in the Spanish database hamper the fulfillment of the requirements of the selection method. Synthetic records were not considered since an appropriate number of records were obtained from the PEER database.

Table 3. Selected PEER NGA strong motion database records, resulting from the conditional spectrum approach

\begin{tabular}{|c|c|c|c|c|c|c|}
\hline $\begin{array}{l}\text { Record } \\
\text { No. }\end{array}$ & Earthquake & $\begin{array}{l}\text { Date } \\
(\mathrm{mm} / \mathrm{dd} / \mathrm{yy})\end{array}$ & Time & $\begin{array}{l}\text { Data } \\
\text { source }\end{array}$ & $\begin{array}{l}\text { Station } \\
\text { ID }\end{array}$ & $\begin{array}{l}\text { PGA } \\
{[\mathrm{g}]}\end{array}$ \\
\hline \multirow[t]{2}{*}{1} & HOLLISTER & $01 / 26 / 86$ & 19:20 & USGS & 1656 & 0.1009 \\
\hline & URL: http://peer.berkeley & ga files/ath/H & TR/D-H & 255.AT2 & & \\
\hline \multirow[t]{2}{*}{2} & COALINGA & $07 / 25 / 83$ & $22: 31$ & CDMG & 1703 & 0.1516 \\
\hline & URL: http://peer.berkeley & ga files/ath/C & $\mathrm{GA} / \mathrm{F}-\mathrm{C}$ & 000.AT2 & & \\
\hline \multirow[t]{2}{*}{3} & MAMMOTH LAKES & $05 / 31 / 80$ & $15: 16$ & USGS & 43 & 0.1452 \\
\hline & URL: http://peer.berkeley & ga files/ath/N & $\mathrm{TH} / \mathrm{D}$ & 090.AT2 & & \\
\hline \multirow[t]{2}{*}{4} & COALINGA & $05 / 09 / 83$ & 02:49 & USGS & 10 & 0.1203 \\
\hline & URL: http://peer.berkeley & ga files/ath/C & GA/A- & N095.AT & & \\
\hline \multirow[t]{2}{*}{5} & CHALFANT & $07 / 31 / 86$ & 07:22 & CDMG & 54171 & 0.1196 \\
\hline & URL: http://peer.berkeley & ga files/ath/C & $\mathrm{NT} / \mathrm{D}-$ & 2270.AT2 & & \\
\hline \multirow[t]{2}{*}{6} & WHITTER NARROWS & $10 / 14 / 87$ & $10: 59$ & CDMG & 14403 & 0.1487 \\
\hline & URL: http://peer.berkeley & ga files/ath/Y & $\mathrm{R} / \mathrm{B}-1$ & 60.AT2 & & \\
\hline
\end{tabular}

The CS method allows to select a set of ground motions whose response spectra (in log scale) individually match the probabilistically generated response spectrum, obtained by performing a Monte-Carlo simulation from a target distribution (Jayaram et al. 2011; NIST 2011). In contrast to other matching procedures, the CS approach includes not only the matching of a target mean, but also the matching of a target variance.

The similarity of the target with the selected ground motion spectra of Fig. 7 is measured using the sum of the squared errors. The matching can also be improved by means of a "greedy" optimization method that replaces each previously selected ground motion by another one from the database (if any) that reduces the differences between the sample and target means and variances. 

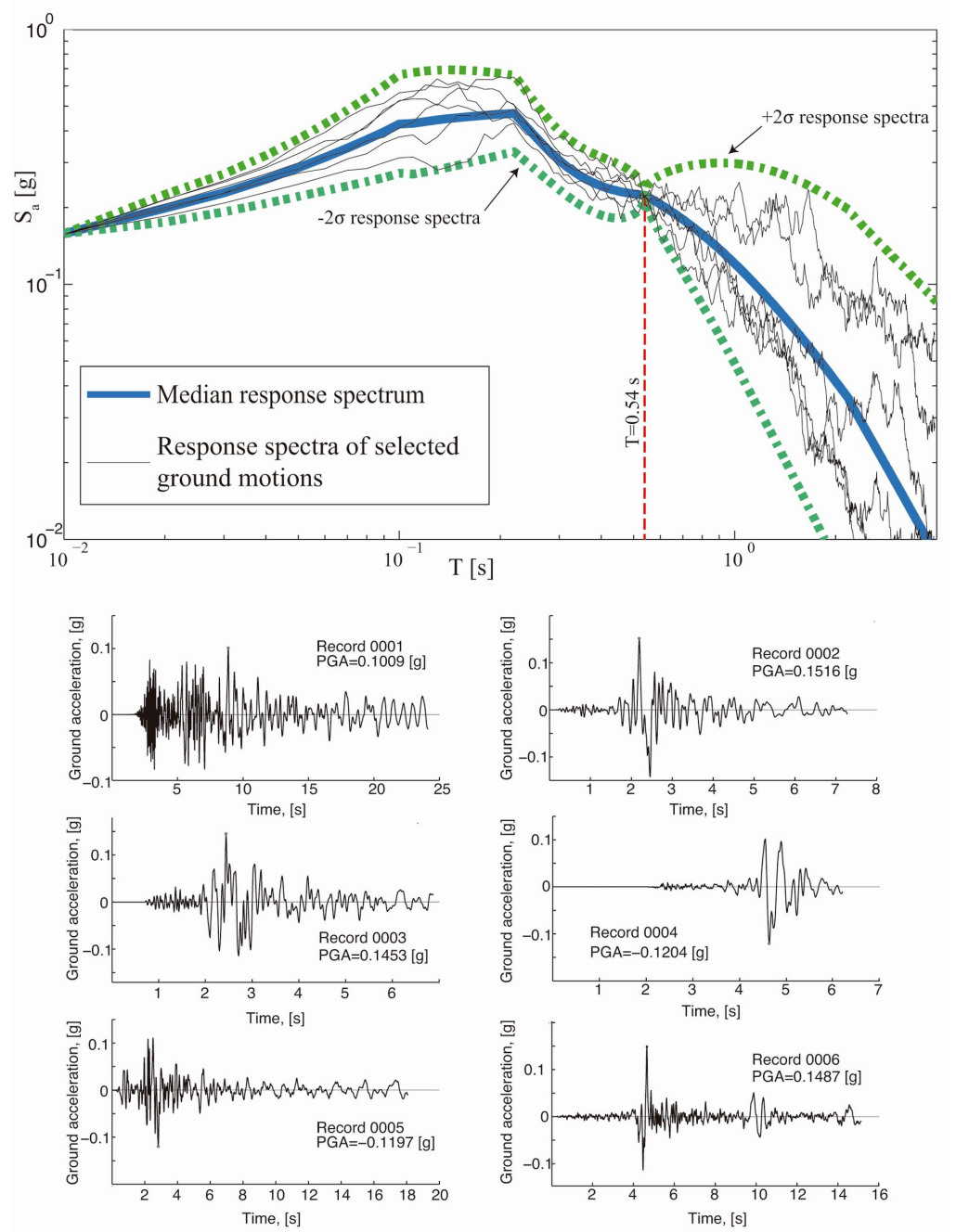

Fig. 7. Record selection according to the conditional spectrum approach with the $5 \%$ damped response spectrum for Soil Zone II of Barcelona as target spectrum.

\subsection{Incremental Dynamic Analysis}

The incremental dynamic analysis (IDA), proposed by Vamvatsikos and Cornell (2002), allows to estimate the structural performance under seismic loads in a systematic way. It can be performed either for a single or for several ground motion records in order to take into account the variability of the demand. Accordingly, the structural model is subjected to one (or more) ground motion record(s), scaled to different PGA values, thus producing one (or more) curve(s) of response, parameterized versus the scaled spectral acceleration values (Fig. 8.). For each incremental value of PGA, the corresponding dynamic response of the building is calculated in function of a control variable, usually the maximum displacement measured, for example, at the roof of the building.

In this study, the six previously described ground motion records (Table 3) were used in order to perform the IDA calculations. The selected range of spectral accelerations was set between $0.01 \mathrm{~g}$ and $0.29 \mathrm{~g}$. IDAs were performed with the TreMuri program while MATLAB (The MathWorks 2009b) was used for the post-processing and comparison of results. 

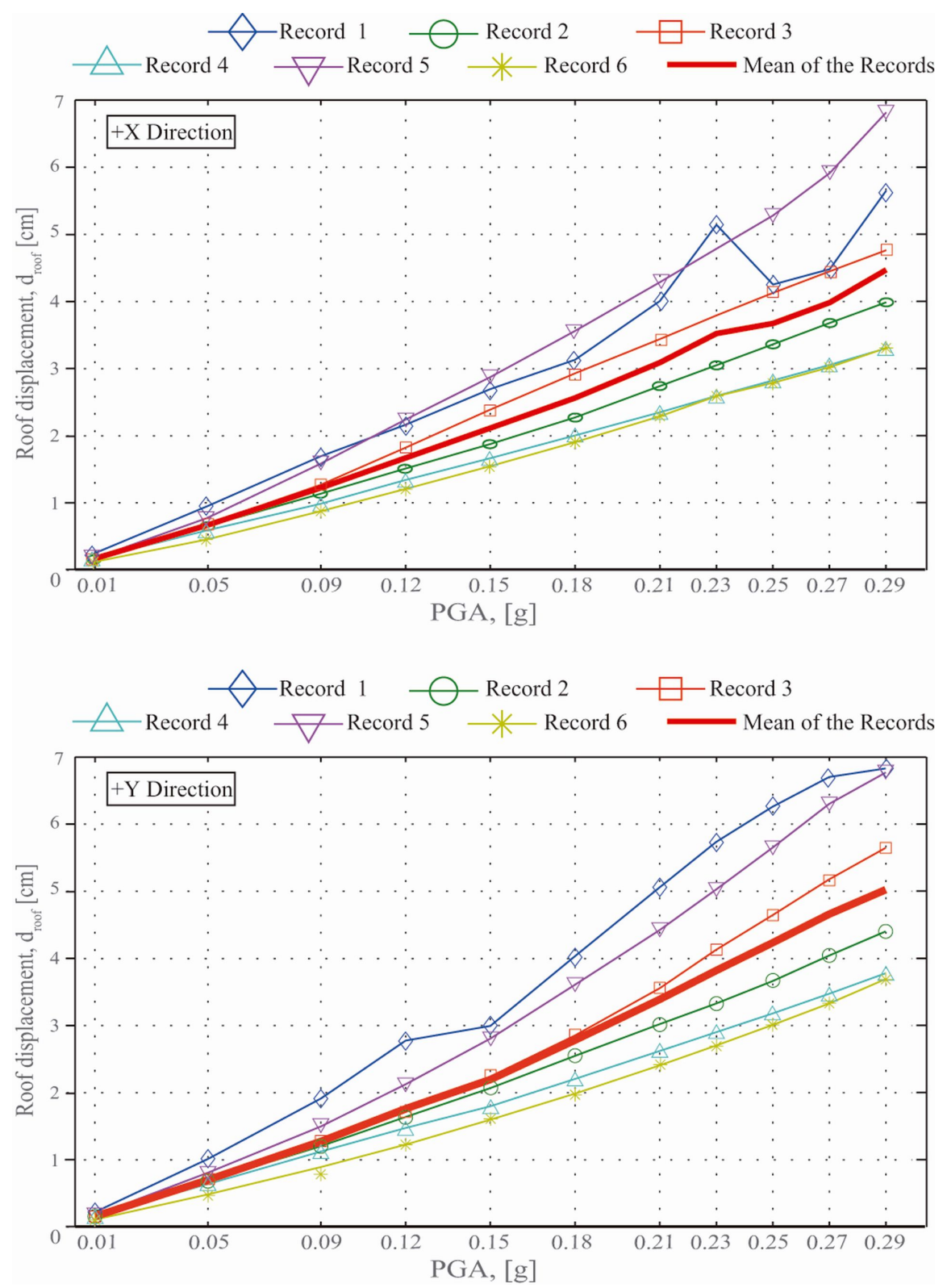

Fig. 8. IDA results for the URM building for both directions. Relationship between PGA and $d_{\text {roof }}$ 


\subsection{Non-linear static procedures and performance point}

The non-linear static procedures (NSPs) are intended to provide a simplified approach to evaluate the nonlinear response behavior of a structure. There are currently different incremental NSPs. Few of them have been recently developed, others are contemporary methodologies, some of which have been adapted and improved (Fajfar 1999; FEMA-440/ATC-55 2005; C.S.LL.PP. 2008). Technical codes and guidelines related to building construction, design, retrofitting and safety, incorporate these NSPs (ATC-40 1996; Eurocode-8-1 2004; FEMA-440/ATC-55 2005). Despite of the conceptual and procedure differences, all the NSPs have common basis and objectives. In summary, two stages in these procedures can be distinguished: a) the capacity computation, and b) the evaluation of the seismic demand. In the first stage, the NSPs are all based on pushover analysis. According to their corresponding rules, the representation of the capacity of the structure in the acceleration-displacement format and its equivalent bilinear representation are obtained from the capacity (pushover) curve and modal analysis parameters for each NSP. Thus, the equivalent bilinear representation of the capacity spectrum is specifically related to the selected NSP. Table 3 includes the parameters obtained from the bilinear representation of the capacity spectrum for each NSP shown in Fig. 9.
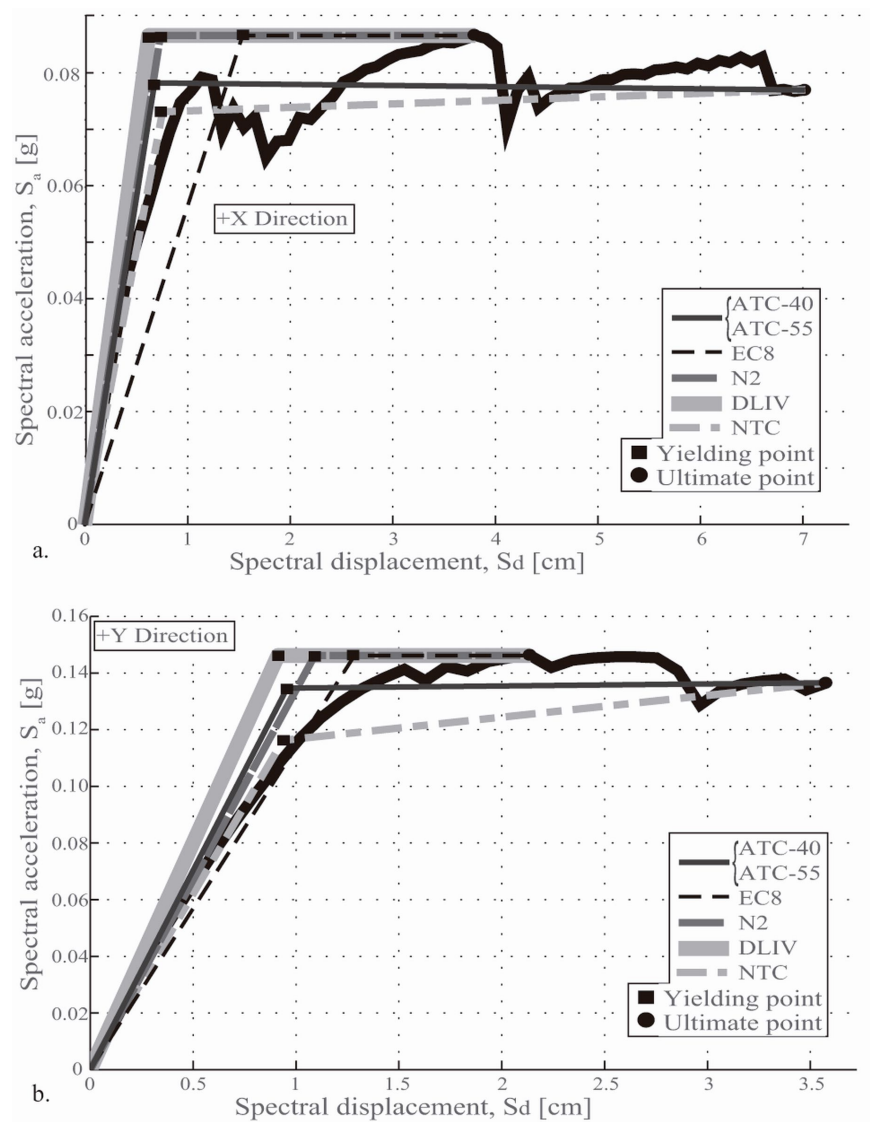

Fig. 9. Bilinear representation, in acceleration-displacement format, of the capacity curve corresponding to the different NSPs. a) $+X$ direction; b) $+Y$ direction. 
Table 4. Bilinear representation parameters for each NSP.

\begin{tabular}{|c|c|c|c|c|c|c|c|c|}
\hline \multirow{3}{*}{ NSP } & \multicolumn{4}{|c|}{$+X$ Direction } & \multicolumn{4}{|c|}{$+Y$ Direction } \\
\hline & \multicolumn{2}{|c|}{ Yield point } & \multicolumn{2}{|c|}{ Ultimate point } & \multicolumn{2}{|c|}{ Yield point } & \multicolumn{2}{|c|}{ Ultimate point } \\
\hline & $\begin{array}{l}\mathbf{S d}_{\mathbf{y}} \\
{[\mathrm{cm}]}\end{array}$ & $\begin{array}{l}\mathrm{Sa}_{\mathrm{y}} \\
{[\mathrm{g}]}\end{array}$ & $\begin{array}{l}\mathbf{S d}_{\mathbf{u}} \\
{[\mathrm{cm}]}\end{array}$ & $\begin{array}{l}\mathrm{Sa}_{\mathrm{u}} \\
{[\mathrm{g}]}\end{array}$ & $\begin{array}{l}\mathbf{S d}_{\mathbf{y}} \\
{[\mathrm{cm}]}\end{array}$ & $\begin{array}{l}\mathrm{Sa}_{\mathrm{y}} \\
{[\mathrm{g}]}\end{array}$ & $\begin{array}{l}\mathbf{S d}_{\mathbf{u}} \\
{[\mathrm{cm}]}\end{array}$ & $\begin{array}{l}\mathrm{Sa}_{\mathrm{u}} \\
{[\mathrm{g}]}\end{array}$ \\
\hline $\begin{array}{l}\text { ATC-40 / } \\
\text { ATC-55 }\end{array}$ & 0.681 & 0.0780 & 7.019 & 0.0768 & 0.957 & 0.1347 & 3.581 & 0.13 \\
\hline EC8 & 1.538 & 0.0864 & 3.807 & 0.0864 & 1.284 & 0.1462 & 2.139 & 0.1462 \\
\hline $\mathrm{N} 2$ & 0.738 & 0.0864 & 3.807 & 0.0864 & 1.091 & 0.1462 & 2.139 & 0.1462 \\
\hline DLIV & 0.623 & 0.0864 & 3.807 & 0.0864 & 0.912 & 0.1462 & 2.139 & 0.1462 \\
\hline NTC & 0.758 & 0.0730 & 7.019 & 0.0768 & 0.937 & 0.1163 & 3.581 & 0.1366 \\
\hline
\end{tabular}

In the second stage, each NSP undertake a different process for the evaluation of the demand in accordance with their corresponding guidelines, obtaining a damped elastic or inelastic response spectra for each ground motion record, as appropriate. Once the capacity and the demand format has been homogenized following a standardized process, each NSP calculate the performance point following its own specific rules that will be summarized next.

- The Capacity Spectrum Method (CSM): originally proposed by Freeman et al. (1975), it is contained in the ATC-40 (1996) guidelines. The method proposes 3 different procedures that mainly differ in the way to obtain the solutions: mathematically or graphically. The first procedure, called Procedure A, is used in this work. The reduction of the 5\% damped elastic response spectrum is performed through the spectral reduction factors for velocity (SRV) and acceleration (SRA). The procedure was proposed for concrete structures and considers an hysteretic factor, $\mathrm{K}$, that takes into account three different hysteretic behaviors for the structure and its components, from a perfect behavior to a deficient one (K1 to K3, respectively). The multi-linear representation of the capacity is obtained through a bilinear representation that equals the area behind the capacity curve, maintaining the initial stiffness in the elastic branch. The performance point is calculated by means of an iterative process which involves the calculation of a new bilinear representation, and hence new reduction factors for each trial point.

- The ATC-55 procedure is contained in the document FEMA-440/ATC-55 (2005). This procedure is an improvement of the ATC-40 (1996) guidelines for concrete structures. The main changes correspond to damping and demand reduction factors. The method presents two main sub-procedures, the Acceleration-Displacement Response Spectrum (ADRS) procedure, and the Modified Acceleration-Displacement Response Spectrum (MADRS). The demand is also calculated from the 5\% damped elastic response spectrum. The calculation of the bilinear representation remains the same as in the ATC-40 procedure.

- The N2 method (N2): proposed by Fajfar (1999). This procedure has evolved and changed in order to take into account higher modes, asymmetric structures, among other aspects. The procedure proposes an elastic-plastic bilinear representation for the capacity, and an inelastic response spectrum for the demand. The bilinear representation considers the spectral displacement/acceleration corresponding to the maximum base shear as the ultimate point of the capacity. This procedure does not consider the possibility of occurrence of hardening or softening for the inelastic branch.

- The EuroCode 8 (EC8) method. The original method included in EC8 was the N2 procedure (Fajfar 1999); nevertheless, it has suffered some modifications mostly in the elastic-plastic 
bilinear representation for capacity (Eurocode-8-1 2004). The inelastic response spectrum is used for the calculation of the demand. The considerations about the ultimate point and the occurrence of hardening or softening in the inelastic branch are the same as the ones considered in $\mathrm{N} 2$.

- The method proposed by De Luca, Iervolino and Vamvatsikos (DLIV) (De Luca et al. 2011). The procedure varies the way of calculating the elastic slope of the elastic-plastic bilinear representation. The inelastic response spectrum is used for the calculation of the demand. The considerations regarding the ultimate point and the occurrence of hardening or softening in the inelastic branch are the same as the ones considered in N2 and EC8.

- The method of the Norme Tecniche per le Costruzioni (NTC-08): it is included in the Italian Construction Code (C.S.LL.PP. 2008). The procedure proposes an elastic-plastic bilinear representation with the possibility to take into account the strength drops after the maximum strength point. The demand is obtained from the inelastic response spectrum. The bilinear representation considers the spectral displacement corresponding to the maximum roof displacement as the ultimate point of the capacity. This procedure considers the possibility of occurrence of hardening or softening for the inelastic branch.

The performance points of the URM building for both directions of analysis have been calculated by means of the six NSPs, each one of them performed by using the six selected ground motion records detailed in Table 3 and scaled for different PGA values (11 in total). The calculations for the IDA method were previously shown in Fig. 8. In order to allow a summarized view of the results, the mean curves corresponding to the different NSPs calculations are shown, combined with the mean curve of the IDAs computations, for both directions (Fig. 10 and Fig. 11).

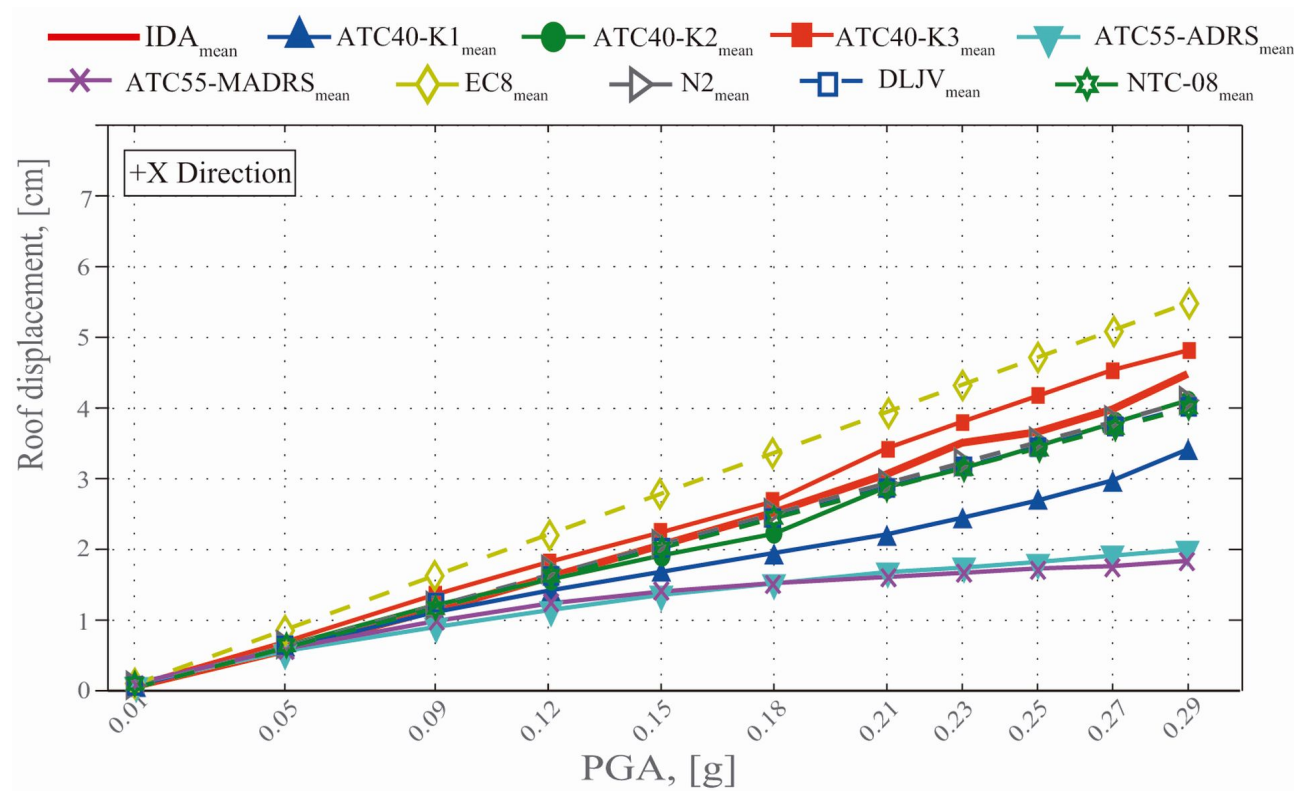

Fig. 10. Comparison between NSPs and IDAs mean results for $+X$ direction. 


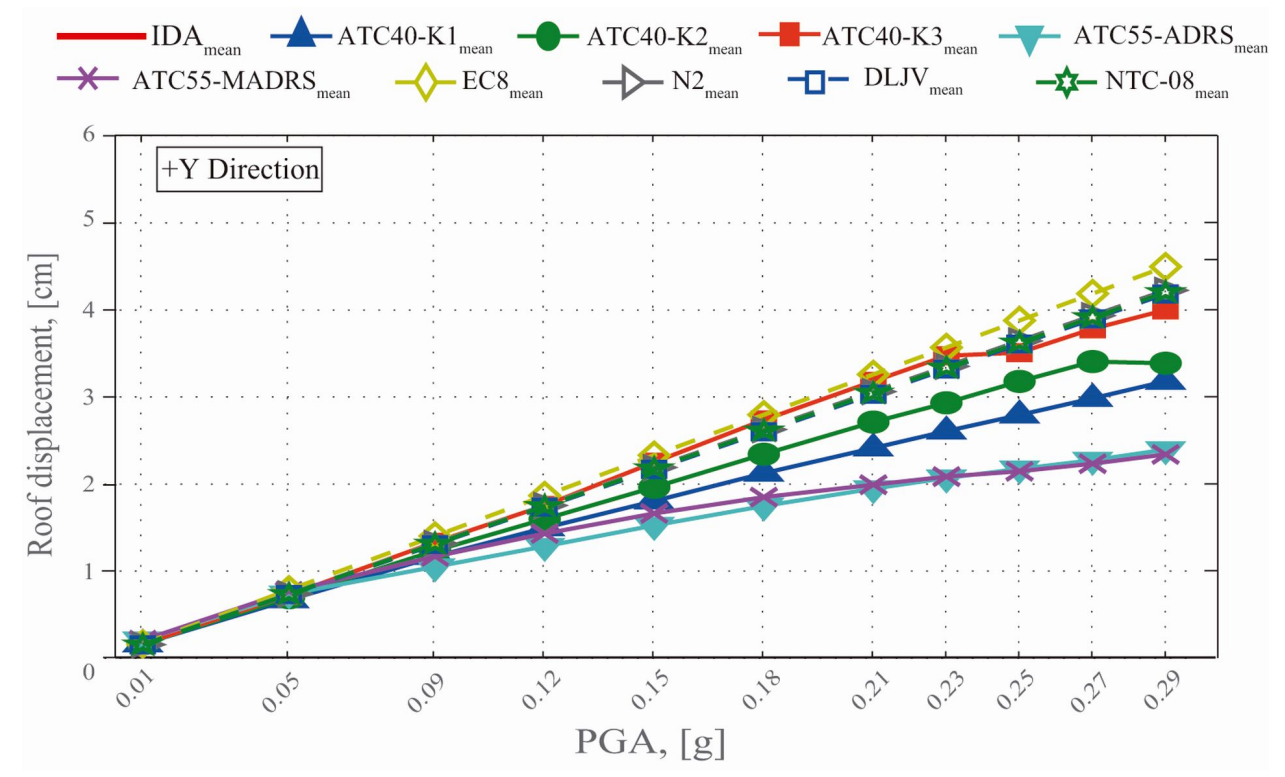

Fig. 11. Comparison between NSPs and IDAs mean results for $+Y$ direction.

\section{FRAGILITY AND DAMAGE CURVES}

\subsection{Fragility}

The assessment of the building behavior requires the definition of different damage limit states, whose calculation and number vary according to the selected methodology to be applied. The $+Y$ direction results of the ATC-40 procedure with an hysteretic factor K2 have been chosen to exemplify this section.

For this work, the method exposed in the RISK-UE project (Milutinovic and Trendafiloski 2003) was used, and four damage limit states were specified - slight $\left(d s_{1}\right)$, moderate $\left(d s_{2}\right)$, severe $\left(d s_{3}\right)$ and complete $\left(d s_{4}\right)$ - (Grünthal 1998; Faccioli and Cauzzi 2006; Barbat et al. 2008; Vargas et al. 2013). These damage limit states are calculated in terms of the yielding point, $\left[S d_{y}, S a_{y}\right]$, and ultimate point $\left[S d_{u}, S a_{u}\right]$ (Lagomarsino et al. 2002), obtained from the bilinear representation of the capacity of the structure in the acceleration-displacement format (Fig.8 and Table 3). A fifth no-damage limit state is also implicitly defined $\left(d s_{0}\right)$.

Fragility curves represent the probability of reaching or exceeding a specific damage limit state in terms of a selected intensity measure parameter (IM). For the purpose of this work, the spectral displacement, $S d$, and the PGA were both selected as the intensity measure parameters. For the nodamage limit state, the fragility curve is trivially equal to one, and for the other defined damage limit states it is assumed that fragility curves follow a lognormal cumulative distribution, which is an adequate option taking into account the physics that undergoes the degrading process (Keneddy et al. 1980).

$$
P\left(d s_{i} \mid I M\right)=\Phi\left(\frac{1}{\beta_{d s_{i}}} \ln \left[\frac{I M}{\overline{I M}_{d s_{i}}}\right]\right)
$$

Where $P\left(d s_{i} \mid I M\right)$ is the probability that a given $I M$ causes the structure to reach the damage state $d s_{i}$, $\Phi$ is the standard normal cumulative distribution function, $\overline{I M}_{d s_{i}}$, is the mean value of the fragility function, and $\beta_{d s_{i}}$ is the standard deviation of $\ln I M$ (Lantada et al. 2009; Baker 2014; Baker 2015). 
In the process undertaken in this section, the yielding and ultimate points have been calculated by performing a specific NSP. Afterwards, both points determine the damage thresholds that have been obtained through the relationships detailed in the RISK-UE project. Therefore, we have as much damage thresholds sets as NSP we use.

\subsubsection{Spectral displacement, $S d$, as IM}

For the case in which the spectral displacement is selected as IM, the mean value of the corresponding fragility curve for each damage state is obtained from the capacity spectrum using simplifying assumptions: a) the seismic damage of the buildings follows a binomial probability distribution (Table 5) or an equivalent beta distribution (Lagomarsino et al. 2002) and b) it is assumed that the probability of exceeding a specific damage state when the building reaches its corresponding threshold spectral displacement is $50 \%$. Consequently, these damage thresholds are represented by the mean values $\overline{S d}_{d s_{i}}$. The damage thresholds (Fig. 12a) are calculated by using the following relations: $\overline{S d}_{1}=$ $0.7 \cdot S d_{y} ; \quad \overline{S d}_{2}=S d_{y} ; \overline{S d}_{3}=S d_{y}+0.25 \cdot\left(S d_{u}-S d_{y}\right)$ and $\overline{S d}_{4}=S d_{u}$ (Lagomarsino et al. 2002).

Table 5. Binomial probability distribution of the different damage states

\begin{tabular}{lllll}
\hline & $\mathrm{P}\left(d s_{1}\right)$ & $\mathrm{P}\left(d s_{2}\right)$ & $\mathrm{P}\left(d s_{3}\right)$ & $\mathrm{P}\left(\mathrm{ds}_{4}\right)$ \\
\hline $\mathrm{P}\left(\mathrm{ds}_{1}\right)=0.5$ & $\mathbf{0 . 5 0}$ & 0.119 & 0.012 & 0.00 \\
$\mathrm{P}\left(\mathrm{ds}_{2}\right)=0.5$ & 0.896 & $\mathbf{0 . 5 0}$ & 0.135 & 0.008 \\
$\mathrm{P}\left(\mathrm{ds}_{3}\right)=0.5$ & 0.992 & 0.866 & $\mathbf{0 . 5 0}$ & 0.104 \\
$\mathrm{P}\left(\mathrm{ds}_{4}\right)=0.5$ & 1.00 & 0.988 & 0.881 & $\mathbf{0 . 5 0}$ \\
\hline
\end{tabular}

The standard deviation, $\beta_{d s_{i}}$, is obtained through a least squares fit of the fragility function to the computed exceedance probabilities, thus completely defining the fragility curves (Fig. 12b).

Therefore, the corresponding spectral displacements obtained from the IDAs and the different NSPs can be used as inputs into their corresponding fragility curves (Fig. 12b), allowing to obtain the probability of each damage limit state at that point $P\left(d s_{i}\right)$, where $i=(0,1,2,3,4)$.

\subsubsection{Peak ground acceleration, PGA, as IM}

When PGA is selected as IM, the estimation of the fragility functions is carried out by means of the Multiple Stripes Analysis (MSA) procedure (Jalayer and Cornel 2009; Peng et al. 2012; Baker 2014; Baker 2015). Once a NSP has been selected, the yielding and ultimate points and the corresponding damage thresholds are calculated as detailed in section 3.1.1. So far, no dynamic analysis has been performed. Then, for each considered $P G A_{\mathrm{j}}$, the probability of occurrence of a determined damage state is calculated by the binomial distribution, through the computation of the fraction of ground motion records (Fig. 12c) in which the damage state in question is reached (Eq.(2)).

$$
P\left(x_{j} \text { occurences in } n_{j} \text { ground motions }\right)=\left(\begin{array}{l}
n_{j} \\
x_{j}
\end{array}\right) P\left(d s_{i}\right)_{j}^{x_{j}} \cdot\left[1-P\left(d s_{i}\right)_{j}\right]^{n_{j}-x_{j}}
$$

Where $x_{j}$ is the number of occurrences, $n_{j}$ is the number of ground motions, $P\left(d s_{i}\right)_{\mathrm{j}}$ is the probability of occurrence of the analyzed damage state in the structure due to a ground motion scaled to the $P G A_{\mathrm{j}}$, as defined in Eq.(1). The method of maximum likelihood (Eq.(3)) is then used to fit this data in order to obtain the fragility function that better reproduces the results from the structural analyses for that damage state (highest probability of having observed them).

For the total number of selected PGAs, $k$, the Likelihood of the data is obtained from the product of the $j$ binomial probabilities, $\Pi$. Substituting Eq. (1) in the likelihood function for multiple PGAs leads to Eq.(3), which is maximized in order to obtain the fragility function parameters (Fig. 12d). 
Likelihood $=\prod_{j=1}^{k}\left(\begin{array}{l}n_{j} \\ x_{j}\end{array}\right) \cdot \Phi\left(\frac{1}{\beta_{d s_{i j}}} \ln \left(\frac{P G A_{j}}{\overline{P G A}_{d s_{i j}}}\right)\right)^{x_{j}} \cdot\left(1-\Phi\left(\frac{1}{\beta_{d s_{i j}}} \ln \left(\frac{P G A_{j}}{\overline{P G A}} d s_{i j}\right)\right)\right)^{n_{j}-x_{j}}$

A detailed explanation on the use of the MSA methodology and the computation of fragility functions can be found in Baker (2015).

In the process undertaken in this section, the yielding and ultimate points have been calculated by performing a specific NSP. Afterwards, both points determine the damage thresholds that have been obtained through the relationships detailed in the RISK-UE project. Accordingly, the fragility curves depend on the results of the IDA and on the specific NSP used to determine the damage thresholds used to perform the MSA, as well. This means that the calculated fragility curves are not intrinsic of the IDA but, on the contrary, these curves depends on the parameters calculated by using each NSP.

In consequence, the fragility curves depend on the specific NSP used to determine the damage thresholds used to perform the MSA, as well as on the used spectral displacements. In turn, these displacements can be given by the performance points for the NSPs, or by the maximum displacements for the IDAs. Therefore, two sets of fragility curves are obtained from the same damage thresholds.
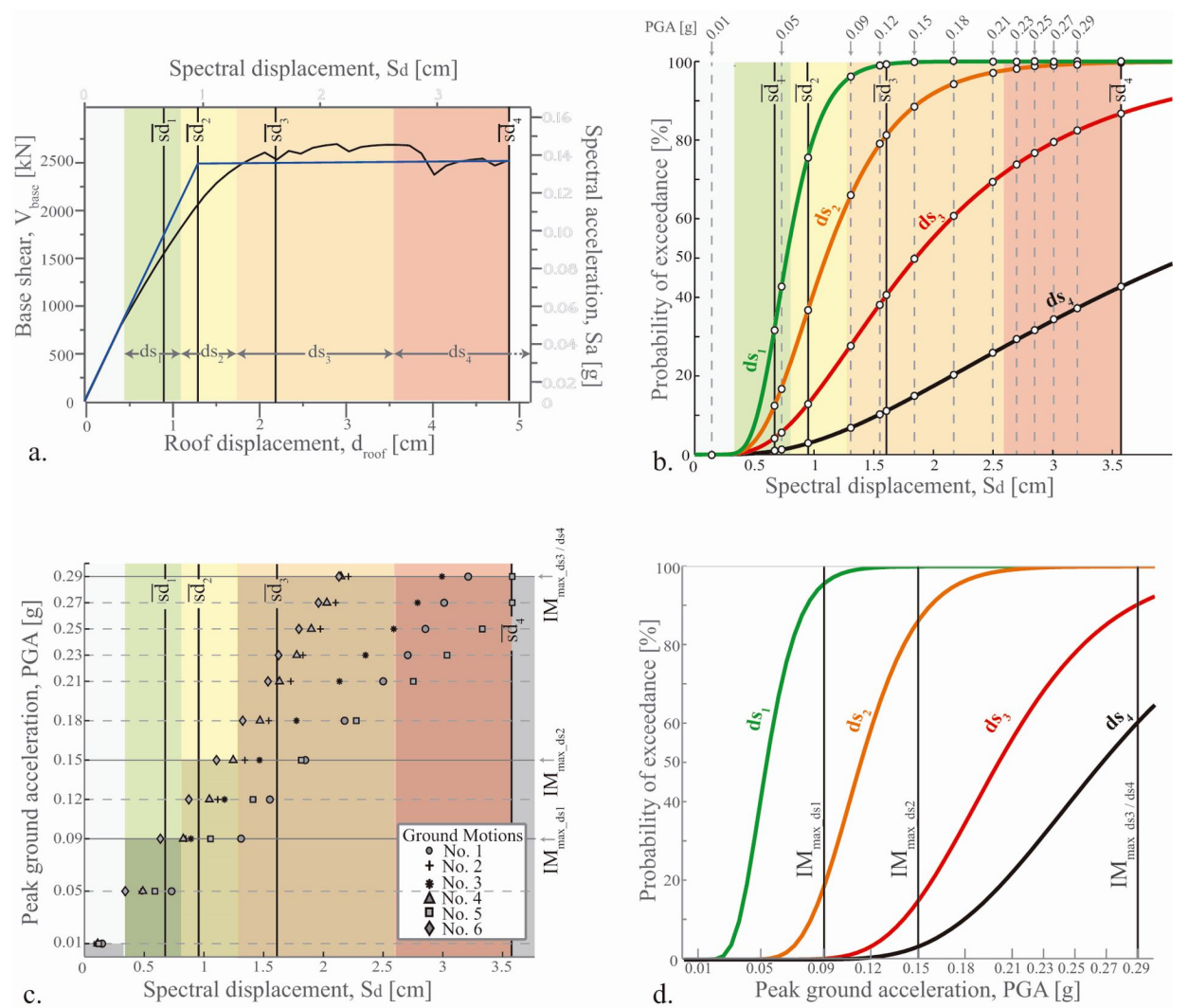

Fig. 12. Damage states and fragility curves for the example method (ATC-40 procedure with hysteretic factor

$\mathrm{K} 2)$. a) Bilinear representation and damage states; b) $\left(S_{d}\right.$ vs $\left.P\left(d s_{i}\right)\right)$ fragility curves for one ground motion, $I M=S_{d} ;$ c) MSA procedure. Spectral displacements for each analyzed PGA for the six ground motions; d) MSA procedure. Fragility curves $\left(P G A\right.$ vs $\left.P\left(d s_{i}\right)\right), I M=P G A$. 


\subsection{Damage}

The procedure used to model and, subsequently, to evaluate the capacity of the buildings, determines the suitable damage index to quantify the accumulated damage by the structure. In our case, the buildings are modeled using macro-elements, and their capacity is evaluated on the basis of an equivalent SDOF system. In consequence, only global response quantities and rough estimations of the global damage can be calculated (Kappos 1997). Therefore, the Damage Index (DI), also known as the mean damage $\left(d_{m}\right)$ value (normalized), has been selected to compute the vulnerability curves. It works as an indicator of the global expected damage of the structure for the selected $I M$ and it is also used to generate seismic risk scenarios in urban areas. The main characteristic of this value is the ease and prompt evaluation of the seismic behavior of the structures. It can be defined from the probabilities calculated previously for the fragility curves, allowing to obtain the so-called vulnerability curves, which plot the expected damage index of the different values of the selected $I M$ (Fig. 13.).

$$
D I=\frac{1}{n} d_{m}=\frac{1}{n} \sum_{i=0}^{n} i \cdot P\left(d s_{i}\right)
$$

where, $D I$ is the damage index, $n$ is the number of non-null damage states, $P\left(d s_{i}\right)$ is the probability that a damage state i occurs, where $i=0,1,2,3,4$; and $d_{m}$ is the mean damage. With regard to the latter, this damage index DI is a quantity in the range $[0,1]$, so that the value of 0 is associated to the absence of damage in the structure, while the value of $1(100 \%)$ is associated to complete damage (full or notrepairable damage). Depending on the selected intensity measure parameter (the spectral displacement, $S d$, or the $P G A$ ) two different sets of fragility curves were built above. Consequently, two sets of damage curves will be defined depending on the chosen intensity measure parameter.

\subsubsection{Spectral displacement, $S d$, as IM}

For each NSP and for each ground motion, a ( $S_{d}$ vs $\left.D I\right)$ vulnerability curve (Fig. 13a) is obtained from Eq.(4). Given a specific NSP and for each scaled ground motion, the spectral displacement of the performance point is calculated. This performance point is related to the PGA to which has been scaled the selected ground motion. Consequently, a DI related to this performance point and, subsequently, related to the PGA of the considered scaled ground motion, is calculated. Following this procedure it is possible to assemble a ( $P G A$ vs $D I)$ vulnerability curve (Fig. 13b) for each ground motion and by using the information included in the $\left(S_{d}\right.$ vs $\left.D I\right)$ vulnerability curve.

\subsubsection{Peak ground acceleration, PGA, as IM}

When PGA is chosen as the IM parameter, the ( $P G A$ vs $D I)$ vulnerability curves (Fig. 13c) can be directly obtained by using Eq. (4) in order to get the probabilities from the corresponding fragility curves calculated in section 3.1.2 on the basis of the MSA. As we detailed there, the obtained damage curves depend not only on the results of the IDA, but also on the undertaken NSP. 

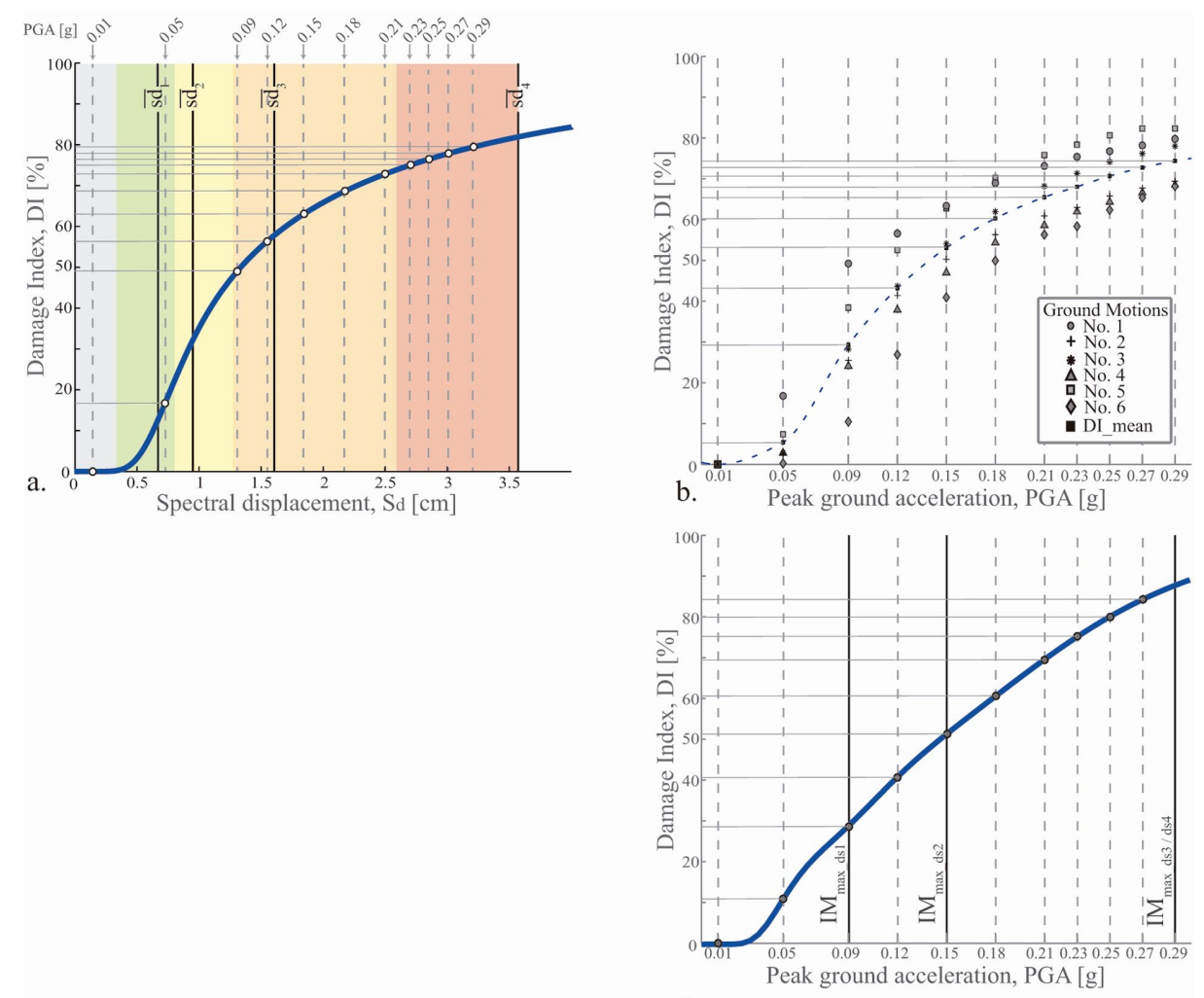

Fig. 13. Vulnerability curves for the example method (ATC-40 procedure with an hysteretic factor K2). a) ( $S d$ vs $D I)$ vulnerability curve for one ground motion, $I M=S_{d}$; b) Mean ( $P G A$ vs $\left.D I\right)$ damage curve for the six ground motions, $I M=S_{d} ;$ c) $(P G A$ vs $D I)$ damage curve for the six ground motions, $I M=P G A$.

\section{Results}

The fragility and damage curves for the IDA approach for both of the selected IM were defined through the bilinear parameters of each NSP. This means that the fragility and damage curves obtained for the IDA approach depend on those parameters and, consequently, those curves are not independent of the NSP. The latter leads to obtain as much sets of IDA fragility and vulnerability curves as NSP are considered for the comparison.

In order to obtain a single damage curve for the IDA, intrinsic to the IDA and independent of any NSP, the parameters (displacements) corresponding to the yielding and ultimate points are calculated from the analysis of the base shear time-history for each PGA of the IDA. Hence, the curve (PGA vs $\left.V_{\text {base_max }}\right)$ is built. The successive drops of Fig. $14\left(d_{\text {Roof }}=2 \mathrm{~cm}\right.$ and $\left.5 \mathrm{~cm}\right)$ may be attributed to similar reasons explained above for the drops observed in Fig. 6 and in Fig. 9. Moreover, in this case the first drop is linked to the yielding of the building while the second one may be attributed to a significant and abrupt decrease of the ductile behavior of the building. For PGA values in which the building behavior remains in the elastic domain, the slope of the (PGA vs $\left.\mathrm{V}_{\text {base } \max }\right)$ curve remains practically uniform. As the building accumulates damage, shifting from elastic to inelastic domain, the slope of the (PGA vs $\mathrm{V}_{\text {base_max }}$ ) curve changes significantly. This results in a change of the first derivative for a PGA, which is identified as the yielding point. With respect to the ultimate point, the same criteria can be applied in some cases, so the ultimate point is associated with the next significant change in the first derivative of the curve (Fig. 14a). Alternatively, the ultimate point can be evaluated by applying a criteria limiting the ductility. In any case, the yielding and ultimate points can be identified from the curve $\left(d_{\text {roof } \max } v s V_{\text {base }}\right.$ ), being the roof displacements related to the PGAs (Fig. 14b). The conversion factors computed for the MDOF system are then used to calculate the yielding and ultimate points in spectral format. Then, these points are used to obtain the fragility curves by using the MSA procedure described in section 3, and by using the PGA as IM. This lead to fragility curves completely intrinsic to the IDA and independent of any NSP. Afterwards, the (PGA vs DI) vulnerability curves can be 
directly obtained by using Eq. (4) in order to get the damage state exceedance probabilities from the corresponding fragility curves. This damage curve, in this work is referred to as base shear (BS) curve.
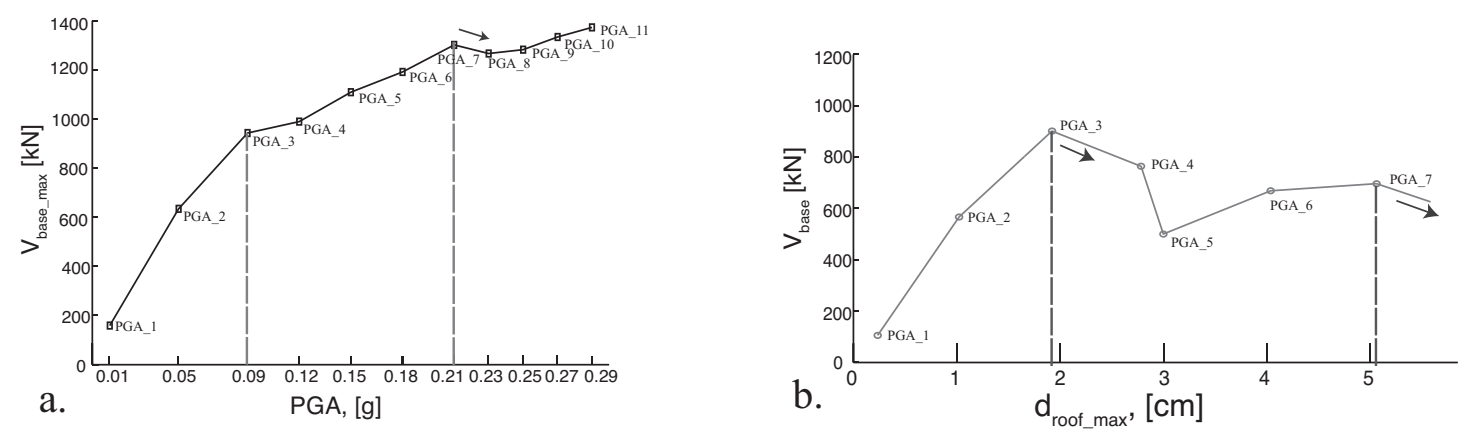

Fig. 14. Selection of the yielding and ultimate points for the IDA. Ground motion $1,+Y$ direction.

A full comparison of the damage curves for $+X$ and $+Y$ directions are shown in Figures 15 and 16 respectively. The Figure 15.al shows the damage curves obtained applying the RISK-UE methodology for each NSPs and by using the spectral displacement $S d$ as intensity measure parameter IM. By applying each NSP, the limit damage states were calculated, and the fragility curves have been built by using the spectral displacement $S d$ as IM. Each ground motion scaled to a specific PGA, allows obtaining the corresponding performance point through an iterative process. This allows to link each calculated performance point to a PGA. Thus, it is possible to calculate the damage index DI related to each calculated performance point which is in turn associated with a value of PGA. This lead to obtain the damage curves. As it can be seen, the results of the IDA are not involved in this process.

In Figure 15.a2, if compared to the previous case (Fig. 15.a1), a variant regarding the calculation of the performance point has been introduced. In this case, the same fragility curves have been used but the performance point associated with each PGA was not calculated by using the iterative process included in the NSPs. Alternatively, the maximum displacement obtained for each IDA was used as performance point. Therefore, this is a mixed procedure that combines the results of the RISK-UE methodology for each NSP (obtaining fragility curves) with the results of IDA (determining the performance point). It is also important to point out that the figure includes a new curve (BS). This curve represents the damage curve intrinsic to the IDA by using the spectral displacement $S d$ as IM. This means that this curve is obtained by using the fragility curves calculated according to the RISKUE methodology, but, using as yielding point and ultimate point those points obtained following the procedure described earlier in this section. Therefore, for the BS curve, the limit damage states do not depend on NSPs.

The Figure 15.b1 shows the damage curves obtained applying the RISK-UE methodology for each NSPs and by using the PGA as intensity measure parameter IM. This means that for each NSP, the limits damage state were defined based on the calculation of the yielding point and the ultimate point as each NSP proposes. But, once the limit damage states are defined, the fragility curves were obtained by performing the MSA methodology described in section 3.1.2.

In Figure 15.b2, if compared to the previous case (Fig. 15.b1), the same variant regarding the calculation of the performance point has been introduced and also the MSA methodology was applied to calculate the fragility curves. However, the performance point associated with each PGA was not calculated by using the iterative process included in the NSPs. Alternatively, the maximum displacement obtained for each IDA was used as performance point. As it has been done in Figure 15.a2, a new damage curve (BS) has been added in Figure 15.b2 and it represents the intrinsic damage curve obtained by using the PGA as IM. This means that this curve is obtained by calculating the fragility curves applying the MSA methodology and by using as yielding point and ultimate point to define the damage limit states, those points obtained following the procedure described at the 
beginning of this section. Consequently, this is the first damage curve completely independent of any NSP.

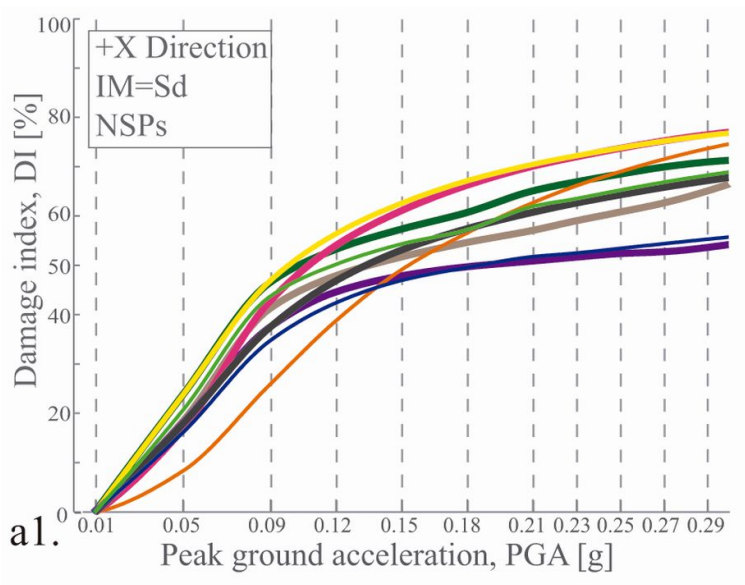

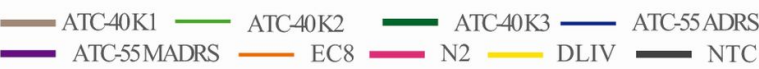

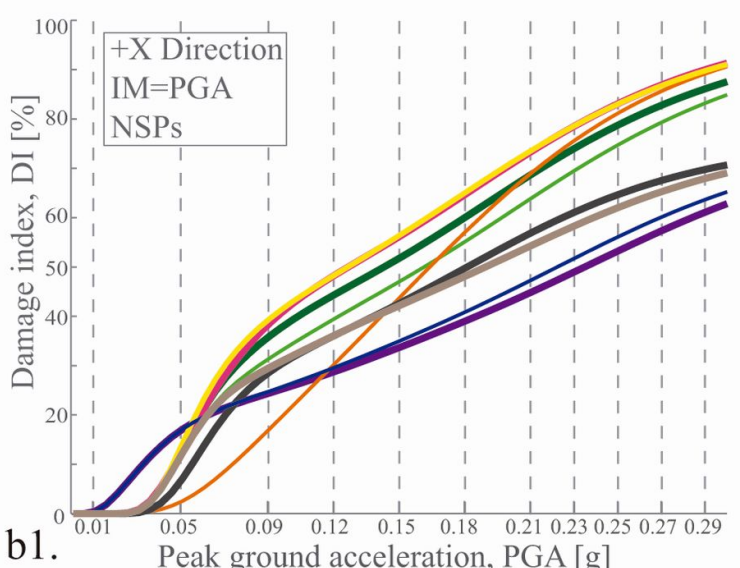

ATC-40K1 - ATC-40K2 $2=$ ATC-40K3 - ATC-55ADRS
ATC-55MADRS $2=$ EC $8=$ NTC

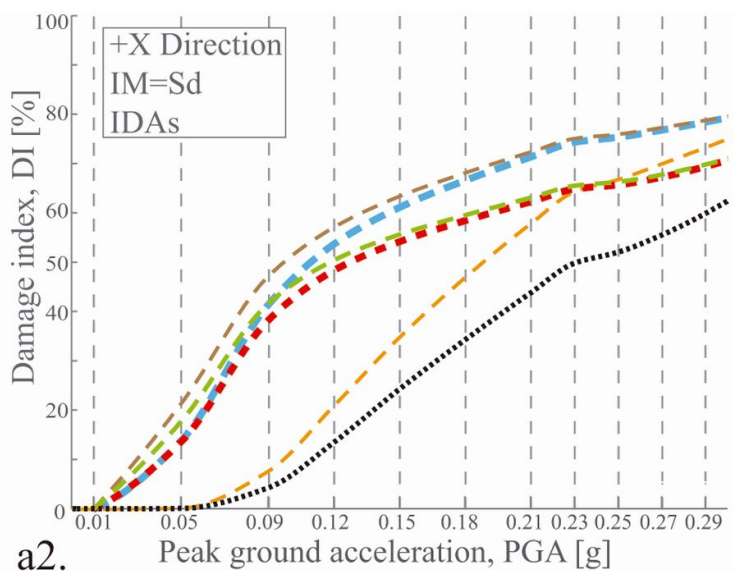

- - ' ATC-40 K1 / ATC-40 K2 / ATC-40 K3 / ATC-55 ADRS / ATC-55 MADRS - EC8 $=-\mathrm{N} 2--\mathrm{DLIV}=-\mathrm{NTC} \ldots . . \mathrm{BS}$

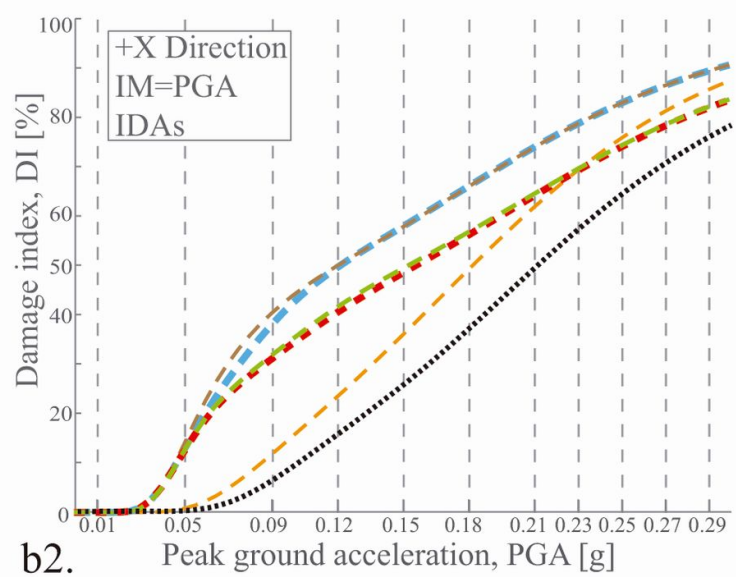

- - ' ATC-40 K1 / ATC-40 K2 / ATC-40 K3 / ATC-55 ADRS / ATC-55 MADRS $-\quad \mathrm{EC} 8=\mathrm{N} 2--\mathrm{DLIV}= \pm \mathrm{NTC} \ldots \ldots \mathrm{BS}$

Fig. 15. Comparison of damage curves ( $+X$ direction). a1)NSPs damage curves - RISK-UE methodology; a2)IDAs damage curves - RISK-UE methodology; b1)NSPs damage curves - MSA methodology; b2)IDAs damage curves - MSA methodology. (Legend: ATC-40 Ki: ATC 40 procedure; ATC-55 (ADRS and MADRS): ATC-55 procedure; EC8: Eurocode 8; N2: method N2; DLIV: De Luca, Iervolino and Vamvatsikos procedure (De Luca et al. 2011); NTC: Norme Tecniche delle Costruzioni -Italian Construction Code- (C.S.LL.PP. 2008); BS: IDA damage curve based on shear base time history). 
Following the structure and the discussion carried out in Figure 15, the same explanation and reasoning can be applied to the analyses performed in the direction $+Y$. The results are exposed in Figure 16.
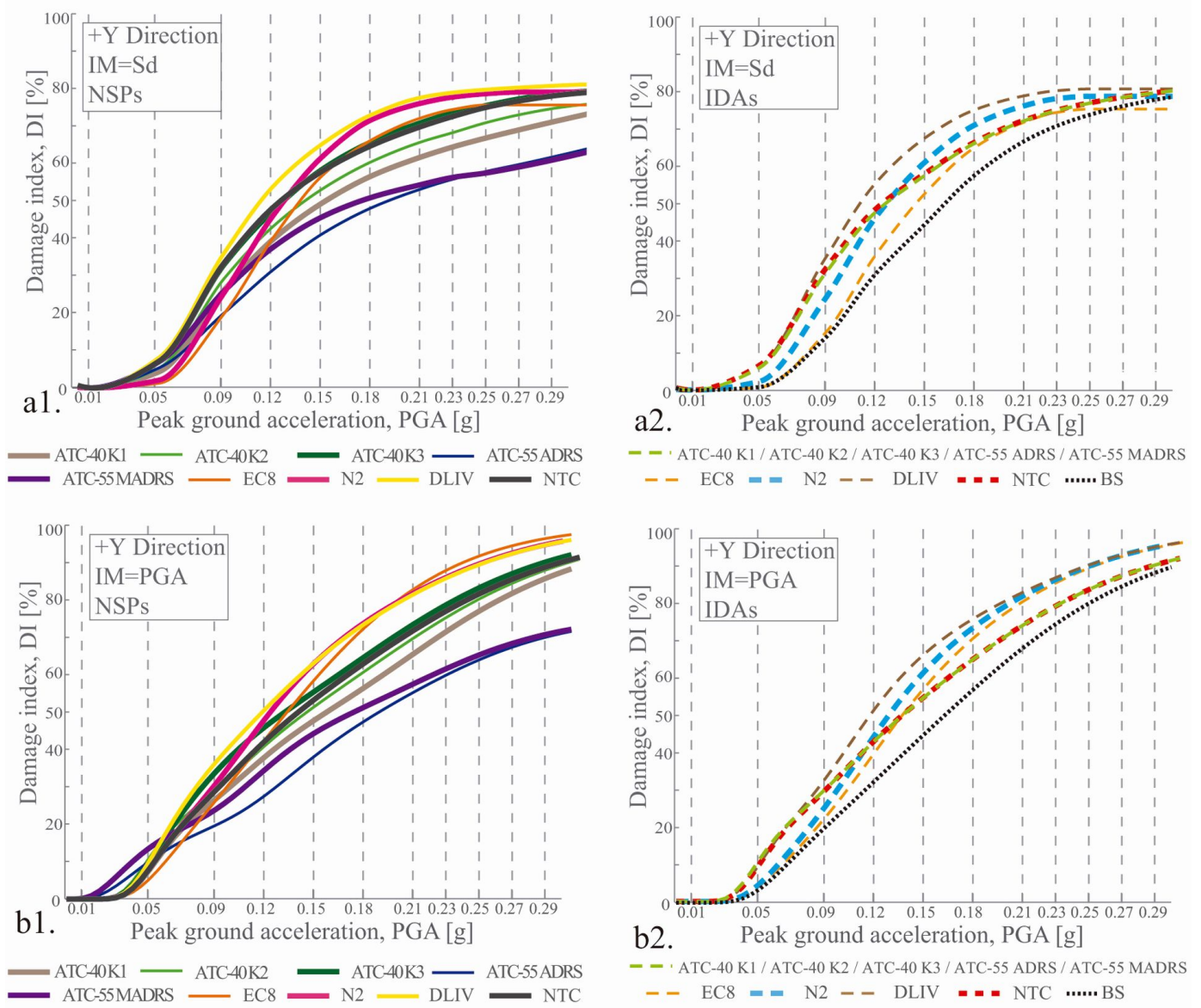

Fig. 16. Comparison of damage curves ( $+Y$ direction). a1)NSPs damage curves - RISK-UE methodology; a2)IDAs damage curves - RISK-UE methodology; b1)NSPs damage curves - MSA methodology; b2)IDAs damage curves - MSA methodology. (Legend: ATC-40 Ki: ATC 40 procedure; ATC-55 (ADRS and MADRS): ATC-55 procedure; EC8: Eurocode 8; N2: method N2; DLIV: De Luca, Iervolino and Vamvatsikos procedure (De Luca et al. 2011); NTC: Norme Tecniche delle Costruzioni -Italian Construction Code- (C.S.LL.PP. 2008); BS: IDA damage curve based on shear base time history).

\section{Discussion and conclusions}

The correct selection and subsequent processing of the ground motion records to be used in any analysis is a task that requires special care. The results obtained are quite sensitive to the process used for the selection of seismic records. For this reason, the consideration of the fundamental period of the building as well as other aspects make the conditional spectrum approach an appropriate option to select the ground motion records that represent the seismic demand.

The definition of the damage limit states depend on the calculation of the yielding and ultimate points whose values vary from one NSP to another. In this work, and once defined the damage limit states, two different methodologies, the RISK-UE and the MSA, are used to obtain the fragility curves which in turn led to the damage curves.

Regarding the conventional NSP (for $+X$ direction: Fig. 15.a1 and Fig. 15.a2), the damage curves obtained applying the procedures DLIV, N2 and NTC are comparable since their bilinear representations are very similar. This is not the case for the EC8 procedure in the $+X$ direction, whose elastic stiffness of its bilinear curve is appreciably lower than the rest due to the process undertaken in 
this procedure for evaluating the yielding point. The ATC-40 and ATC-55 procedures present, in general, lower values of the damage indices if compared with the previously mentioned group of procedures. The main difference lays in the iterative process undertaken to calculate the performance point. In the case of the ATCs procedures, this process includes modifying the damped elastic response spectrum to be used, while the preceding procedures use the 5\% damped inelastic spectrum obtained in accordance to the ductility and the stiffness coefficient of the inelastic domain.

The damage curves calculated for each NSP through the methodology detailed in the RISK-UE (for $+X$ direction: Fig. 15.a1 and Fig.15.a2), present an asymptotic trend as the PGA is increased. So in this case, even for great values of the PGA, the damage index of $100 \%$ is not reached. Alternatively, the obtained damage curves performing the MSA (for $+X$ direction: Fig. 15.b1 and Fig.15.b2) generate, as the PGA increases, damage indices higher than those obtained applying the RISK-UE methodology. In this case it is even possible to reach, given a great value of the PGA, a $100 \%$ of damage index. This behavior is observed in both analyzed directions.

For both methods, RISK-UE and MSA, the trend shown above is not completely followed by two subprocedures of the ATC-55 and the K1 hysteretic factor subprocedure of the ATC-40. The latter can be related to the use of highly damped elastic response spectra, as well as to the iterative procedure included in both subprocedures, which differs from the other NSPs. The factors involved in the calculation process were established from observations and experimental data from the analysis of damage in reinforced concrete structures. Therefore, it would be necessary to introduce some specific modifications of these factors with the aim of adapting the ATC procedures to URM structures and to better represent their behavior.

The observed irregularities in some of the damage curves are caused by the use of a non-homogeneous PGA sampling as well as by the use of six different ground motions records. The use of an homogeneous and higher PGA sampling rates, and the use of more ground motion records would smooth these irregularities in those damage curves.

The damage curves obtained by using the $S d$ as IM and performing the Risk-UE methodology (for $+X$ direction: Fig. 15.a1 and Fig. 15.a2) show an asymptotic trend of the damage index when the PGA increases. On the contrary, this trend is not achieved by the damage curves obtained by using the PGA as IM and the MSA methodology (for $+X$ direction: Fig. 15.b1 and Fig. 15.b2). Moreover, in this case, for low values of the PGA, the damage indices are lower than those obtained by performing the RiskUE methodology and, for higher values of the PGA, the damage indices clearly increase and go over the presumed asymptotic tendency.

In this context, the BS damage curve, obtained by using the PGA as IM and performing the MSA methodology (Fig. 15.b2, for $+X$ direction and Fig. 16.b2, for $+Y$ direction) is independent of any parameter obtained in the NSP and can be considered as intrinsic to the IDA. Accordingly, this curve can be considered as a reference damage curve when dynamic analyzes are available. In this study, the comparison of this reference curve with damage curves obtained by performing the NSP and by applying the Risk-UE methodology seems indicate that the NSP indexes overestimate the damage corresponding to low values of the PGA and underestimate the damage for higher values of the PGA. This trend is followed by all NSP.

The procedures calibrated for reinforced concrete structures are not completely transferable to unreinforced masonry buildings. An additional analytical and experimental work with elements and unreinforced masonry structures is needed to provide more accurate performance and reduction parameters. It is suitable taking with caution the results of the different NSP for unreinforced masonry buildings which have been widely used in the literature. Consequently, a main conclusion should be to use with caution NSP with unreinforced masonry buildings since the results may not be conservative in damage assessment studies, especially when significant values of the PGA are reached.

Among other effects, some can be identified as responsible of the evidenced differences: 1) The use of reduction methods initially parameterized for reinforced concrete buildings; 2) The spectral 
displacements are higher in the IDA due to the possible intervention of higher modes during the analysis and due to the presence of irregularities. These aspects, probably, collaborates in the IDA, while, on the contrary, they are not involved in the NSP.

\section{Acknowledgements and funding}

This research has been partially funded by the government of Spain (Ministerio de Economía y Competitividad-MINECO) and by the Fondo Europeo de Desarrollo Regional (FEDER) of the European Union (UE) through projects referenced as: CGL2011-23621 and CGL2015-65913-P (MINECO / FEDER, UE).

\section{References}

ABRAHAMSON, N. A. \& AL ATIK, L. 2010. Scenario Spectra for Design Ground Motions and Risk Calculation. 9th US National and 10th Canadian Conference on Earthquake Engineering. Toronto, Canada.

ATC-40 1996. Seismic Evaluation and Retrofit of Concrete Buildings. California, U.S.A.: California Seismic Safety Commission.

BAKER, J. W. 2014. Code supplement to efficient analytical fragility function using dynamic structural analysis. http://purl.stanford.edu/sw589ts9300.

BAKER, J. W. 2015. Efficient analytical fragility function fitting using dynamic structural analysis. Earthquake Spectra, 31(1), 579-599.

BARBAT, A. 1982. Cálculo sísmico de estructuras. Barcelona, Editores Técnicos Asociados.

BARBAT, A., YÉPEZ, F. \& CANAS, J. A. 1996. Damage scenarios simulation for risk assessment in urban zones. Earthquake Spectra, 2, 371-394.

BARBAT, A.H., AND BOZZO, L.M. 1997. Seismic analysis of base isolated buildings, Archives of Computational Methods in Engineering, 4(2), 153-192.

BARBAT, A., OLLER, S. \& VIELMA, J. C. 2005. Cálculo y diseño sismorresistente de edifícios: aplicación de la norma NCSE-02,. In: BARBAT, A. (ed.) Monografías de Ingeniería Sísmica. Barcelona, España: Centro Internacional de Métodos Numéricos en Ingeniería.

BARBAT, A. H., PUjADES, L. G., LANTADA, N. \& MORENO, R. 2008. Seismic damage evaluation in urban areas using the capacity spectrum method: application to Barcelona. Soil Dynamics and Earthquake Engineering, 28, 851-865.

BARBAT, A., CARREÑO, M. L., PUJADES, L., LANTADA, N., CARDONA, O. D. \& MARULANDA, M. C. 2010. Seismic vulnerability and risk evaluation methods for urban areas. A review with application to a pilot area. Structure and Infrastructure Engineering, 6, 17-38.

BARBAT, A.H, CARREÑO, M.L., CARDONA, O.D. Y MARULANDA, M.C. 2011. Evaluación holística del riesgo sísmico en zonas urbanas. Revista internacional de métodos numéricos para cálculo y diseño en ingeniería, 27(1), 3-27.

BENEDETTI, D. \& PETRINI, V. 1984. Sulla vulnerabilità sismica degli edifici in muratura: proposta di un metodo di valutazione. L'Industria delle Costruzioni. Roma.

BERNARDINI, A. 2000. The vulnerability of buildings -evaluation on a national scale of the seismic vulnerability of ordinary buildings. CNR-GNDT. Rome, Italy. 
BUSQUETS, J. \& COROMINAS-AYALA, M. 2009. Cerdà i la Barcelona del futur: realitat versus projecte, Barcelona.

C.S.LL.PP. 2008. Decreto Ministeriale del 14 gennaio 2008. Nuove norme tecniche per le costruzioni. Gazzetta Ufficiale della Repubblica Italiana, 4 febbraio 2008.

CENTRE DE CULTURA CONTEMPORÀNIA DE BARCELONA (CCCB). Ordenanzas de edificación [Online]. Available: http://www.anycerda.org/web/es/arxiu-cerda/fitxa/ordenances-dedificacio/329.

CID, J. 1998. Zonación sísmica de la ciudad de Barcelona basada en métodos de simulación numérica de efectos locales. PhD., Universitat Politècnica de Catalunya, UPC.

D'AYAlA, D., Meslem, A., VAMVATSiKOS, D., PORTER, K. \& ROSSETO, T. 2015. Guidelines for Analytical Vulnerability Assessment of Low/Mid-Rise Buildings. In: PROJECT, G. C. (ed.).

DE LUCA, F., IERVOLINO, I. \& VAMVATSIKOS, D. 2011. Improving the Static Pushover Analysis in the Italian Seismic Code by Proper Piece-wise-linear Fitting of Capacity Curves. ANIDIS2011 Convention on Seismic Engineering, 2011. Bari, Italy.

EUROCODE-8-1. 2004. Design of Structures for Earthquake Resistance. Part 1: General Rules, Seismic Actions and Rules for Buildings. Comité Européen de Normalisation.

FACCIOLI, E. \& CAUZZI, C. 2006. Macroseismic intensities for seismic scenarios estimated from instrumentally based correlations. First European Conference on Earthquake Engineering and Seismology (a joint event of the 13thECEE \& 30th General Assembly of the ESC), 2006. Genève, Switzerland.

FAJFAR, P. 1999. Capacity Spectrum Method Based on Inelastic Demand Spectra. Earthquake Engineering and Structural Dynamics, 979-993.

FARDIS, M. N. 2009. Seismic Design, Assessment and Retrofitting of Concrete Buildings based on EN-Eurocode 8, New York, Springer.

FEMA-440/ATC-55. 2005. Improvement of Nonlinear Static Seismic Analysis Procedures. California, U.S.A.: Federal Emergency Management Agency.

FEMA/NIBS 1999. HAZUS'99 technical manual: Earthquake loss estimation methodology. Federal Emergency Management Agency and National Institute of Building Sciences (FEMA/NIBS), Washington DC.

FREEMAN, S. A., NICOLETTI, J. P. \& TYRELL, J. V. Evaluation of Existing Buildings for Seismic Risk - A Case Study of Puget Sound Naval Shipyard. U.S. National Conference on Earthquake Engineering, 1975 Bremerton, Washington. EERI, 113-122.

GALASCO, A., LAGOMARSINO, S. \& PENNA, A. 2002. TREMURI Program: Seismic Analysis of 3D Masonry Building. University of Genoa.

GAMBAROTTA, L. \& LAGOMARSINO, S. 1997a. Computational models for the seismic response of damaging structures. In: ABRAMS, D. P. \& CALVI, G. M. (eds.) U.S.-Italian Workshop on Seismic Evaluation and Retrofit. Columbia University, New York City: National Center for Earthquake Engineering Research. 
GAMBAROTTA, L. \& LAGOMARSINO, S. 1997b. Damage models for the seismic response of brick masonry shear walls, Part II: the continuum model and its applications. Earthquake Engineering and Structural Dynamics, 26(4), 441-462.

GARCIA ESPUCHE, A. 1990. El Quadrat d'Or. Centre de la Barcelona modernista. La formació d'un espai urbà privilegiat, Barcelona, Spain.

GIOVINAZZI, S. \& LAGOMARSINO, S. 2002. WP04: guidelines for the implementation of the I level methodology for the vulnerability assessment of current buildings. Risk-UE report,. Genoa, Italy.

GNDT. 1994. Scheda di esposizione e vulnerabilita` e di rilevamento danni di primo livello e secondo livello (muratura e cemento armato). In: GRUPPO NAZIONALE PER LA DIFESA DAI TERREMOTI (ed.). Roma, Italy.

GONZÁLEZ-DRIGO, R., AVILA-HARO, J., BARBAT, A., PUJADES, L., VARGAS, Y., LAGOMARSINO, S. \& CATTARI, S. 2015. Modernist URM buildings of Barcelona. Seismic Vulnerability and Risk Assessment. International Journal of Architectural Heritage, 9, 214-230.

GONZÁlEZ-DRIGO, R., PÉREZ-GARCÍA, V., DICAPUA, D. \& PUJADES, L. 2008. GPR survey applied to modernist buildings in Barcelona: The cultural heritage of the College of Industrial Engineering. Journal of Cultural Heritage, 9, 196-202.

GRÜNTHAL, G. 1998. European Macroseismic Scale 1998 (EMS-98). Cahiers du Centre Européen de Géodynamique et de Séismologie. Luxembourg: Centre Européen de Géodynamique et de Séismologie.

HAZUS 2012. HAZUS-MH 2.1 Technical Manual. Earthquake Model. In: HOMELAND SECURITY \& FEDERAL EMERGENCY MANAGEMENT AGENCY (eds.). Washington, D.C., USA.

IRIZARRY, J., GOULA, X. \& SUSAGNA, T. 2003. Analytical Formulation for the Elastic Acceleration-Displacement Response Spectra Adapted to Barcelona Soil Conditions. Barcelona, Spain: Institut Cartogràfic de Catalunya.

JALAYER, F. \& CORNEL, C. A. 2009. Alternative Nonlinear Demand Estimation Methods for Probability-Based Seismic Assessments. Earthquake Engineering and Structural Dynamics, 38, 951972.

JAYARAM, N., LIN, T. \& BAKER, J. W. 2011. A Computationally Efficient Ground Motion Selection Algorithm for Matching a Target Response Spectrum Mean and Variance. Earthquake Spectra, 27, 797-815.

KAPPOS, A. J. 1997. Seismic damage indices for RC buildings: evaluation of concepts and procedures. Progress in Structural Engineering and Materials, 1, 78-87.

KENEDDY, R. P., CORNEL, C. A., CAMPBELl, R. L., KAPLAN, S. \& PERLA, H. F. 1980. Probabilistic Seismic Safety Study of an Existing Nuclear Power Plant. Nuclear Engineering and Design, 59, 315-338.

KRESLIN, M. \& FAJFAR, P. 2012. The extended N2 method considering higher mode effects in both plan and elevation. Bulletin of Earthquake Engineering, 10, 695-715.

LAGOMARSiNO, S., GALASCO, A. \& PENNA, A. 2002. Pushover and dynamic analysis of URM buildings by means of a non-linear macro-element model. International Conference on Earthquake Loss Estimation and Risk Reduction. Bucharest: RISK-UE project. 
LAGOMARSINO, S. \& PENNA, A. 2003. Guidelines for the implementation of the II level vulnerability methodology. WP4: Vulnerability assessment of current buildings. RISK-UE project: An advanced approach to earthquake risk scenarios with application to different European towns.

LANTADA, N. 2007. Aplicación de Técnicas GIS a Estimación de Riesgos Naturales. PhD, Universitat Politècnica de Catalunya.

LANTADA, N., PUJADES, L. \& BARBAT, A. 2009. Vulnerability index and capacity spectrum based methods for urban seismic risk evaluation. A comparison. Natural Hazards, 51, 501-524.

LANTADA, N., IRRIZARI, J., BARBAT, A.H., GOULA, X., ROCA, A., SUSAGNA, T. AND PUJADES, L.G. 2010. Seismic hazard and risk scenarios for Barcelona, Spain, using the Risk-UE vulnerability index method, Bulletin of Earthquake Engineering, 8, 201-229.

MILUTINOVIC, Z. V. \& TRENDAFILOSKI, G. S. 2003. WP4: Vulnerability of Current Buildings. RISK-UE Project Handbook.

NIST 2011. Selecting and Scaling Earthquake Ground Motions for Performing Response-History Analyses, NIST GCR 11-917-15. Gaithersburg, Maryland: by NEHRP Consultants Join Venture for the National Institute of Standards and Technology.

PARICIO, A. 2001. Secrets d'un Sistema Constructiu. Barcelona, España. Edicions UPC.

PECKER, A. 2007. Soil structure interaction structure. Chapter In: Earthquake Engineering analysis. Pecker A Ed. Springer.Wien New York. pp. 33-43.

PEER 2011. New Ground Motion Selection Procedures and Selected Motions for the PEER Transportation Research Program. California, USA: Pacific Earthquake Engineering Research Center.

PENG, N., WANG, S. H., JIANG, L. \& HUANG, R. Q. 2012. Seismic Risk Assessment of Structures Using Multiple Stripe Analysis. Applied Mechanics and Materials, 226-228, 897-900.

PENNA, A. 2002. A Macro-element Procedure for the Non-linear Dynamic Analysis of Masonry Buildings. Ph.D., Politecnico di Milano.

PÉREZ-GARCÍA, V., GONZÁLEZ-DRIGO, R. \& SALA, R. 2012. Ground-penetrating radar resolution in cultural heritage applications. Near Surface Geophysics, 10, 77-87.

PIET-70 1971. Obras de Fábrica, Madrid, Torroja, I.E.

PRIESTLEY, M. J. N., SEIBLE, F. \& CALVI, G. M. 1996. Seismic Design and Retrofit of Bridges, New York, John Wiley and Sons.

PUJADES, L., BARBAT, A., GONZÁLEZ-DRIGO, R. \& AVILA-HARO, J. 2012. Seismic Performance of a Block of Buildings Representative of the Typical Construction in the Eixample District in Barcelona (Spain). Bulletin of Earthquake Engineering, 331-349.

SECANELL, R., GOULA, X., SUSAGNA, T., FLETA, J. \& ROCA, A. Analysis of Seismic Hazard in Catalonia (Spain) through Different Probabilistic Approaches. Proceedings of the 11th European Conference on Earthquake Engineering, 1998 Paris, France. Balkema.

SECANELl, R., GOUlA, X., SUSAGNA, T., FLETA, J. \& ROCA, A. 2004. Seismic hazard zonation of Catalonia, Spain, integrating uncertainties. Journal of Seismology, 8, 24-40. 
SUSAGNA, T. \& GOUlA, X. 1999. Cataleg de Sismicitat. Atlas Sismic de Catalunya. In: CATALUNYA, I. C. F. D. (ed.). Barcelona.

THE MATHWORKS, I. 2009b. MATLAB Release 2009b Massachusetts, United States.

VAMVATSIKOS, D. \& CORNELL, C. A. 2002. Incremental Dynamic Analysis. Earthquake Engineering and Structural Dynamics, 31, 491-514.

VARGAS, Y.F., PUJADES, L.G., BARBAT, A.H. AND HURTADO, J.E. 2013. Capacity, fragility and damage in reinforced concrete buildings: a probabilistic approach. Bulletin of Earthquake Engineering, 11(6), 2007-2032. 